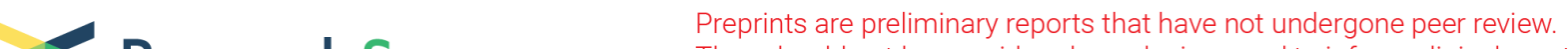 Research Square
or referencend by the media as validated information.
}

\section{Low-Dose Fractionated Irradiation Selectivly Regulate CSPGs and PNNs, Promote Serotonergic Axonal Regeneration}

Qiang Zhang ( $\sim$ zhangqiang_glia@126.com )

Tongji Hospital of Tongji Medical College of Huazhong University of Science and Technology https://orcid.org/0000-0002-3680-6394

Jiao Xu

Tongji Hospital of Tongji Medical College of Huazhong University of Science and Technology

Xiaoxiao Xiong

Tongji Hospital of Tongji Medical College of Huazhong University of Science and Technology

Bifeng Zhu

Tongji Hospital of Tongji Medical College of Huazhong University of Science and Technology

\section{Bo Zhu}

Tongji Hospital of Tongji Medical College of Huazhong University of Science and Technology

\section{Ying Xiong}

Tongji Hospital of Tongji Medical College of Huazhong University of Science and Technology https://orcid.org/0000-0002-6270-5220

\section{Wei Wang}

Tongji Hospital of Tongji Medical College of Huazhong University of Science and Technology

\section{Research Article}

Keywords: CS-A, CS-C, PNNs, 5-hydroxytryptamine, low-dose fractionated therapy, axonal regeneration

Posted Date: July 9th, 2021

DOl: https://doi.org/10.21203/rs.3.rs-514017/v1

License: (c) (i) This work is licensed under a Creative Commons Attribution 4.0 International License. Read Full License 


\section{Abstract}

Chondroitin sulphate proteoglycans (CSPGs) are major components to impeding axonal regeneration, condense in the extracellular-matrix to form perineuronal nets (PNNs) which interdigitate with axonal contacts. Each CSPG comprises a core protein with covalently attached chondroitin-sulfate glycosaminoglycan side chains (CS moieties). In the past, the representative treatment for CSPGs were chondroitinase-ABC which destroys all CS moieties. However, recent rodents researches found some CS moieties promote axon regeneration rather than inhibit axon regeneration. Using a canine model of spinal cord injury ( $\mathrm{SCl}$ ), which is a superior translational model for progressing rodent data into clinical practice, we showed that specific sulfation patterns of CS moieties play different role in modulation of axon regrowth. Upregulated CS-A expression occurred at 1-day post-SCl, earlier than CS-C expression which was increased at 14-days post-SCI. CS-A was mainly colocalized with astrocytes but CS-C was upregulated in both astrocytes and neurons/axons. Treatment with low-dose fractionated irradiation (LDI) significantly inhibited the expressions of astrocyte-associated CS-A and CS-A-enriched PNNs, but no inhibitory effect on CS-C and CS-C-enriched PNNs. There was a positive correlation between a reduction of CS-A-enriched PNNs and an increase of serotonergic (5-hydroxytryptamine, 5-HT) axonal sprouting. Increased serotonergic axon sprouting proximal to the lesion accompanied $5 \mathrm{HT}$ receptor up regulation following LDI treatment. Furthermore, LDI treatment promoted hindlimb motor function recovery following SCI. Taken together, our findings show that specific sulfation patterns of CS moieties and CSPG-enriched PNNs involved in carrying instructions for regulating axonal regeneration and that LDI treatment may be an efficacious strategy for treating $\mathrm{SCl}$.

\section{Introduction}

Spinal cord injury (SCl) causes severe sensorimotor dysfunctions, which induces long-term life difficulties in affected individuals. Axonal regeneration and re-innervation have emerged as important mechanisms underlying functional recovery processes following SCI (Tohda and Kuboyama 2011; Fink et al. 2017; O'Shea et al. 2017). Recent evidence suggests that many repulsive cues inhibit regenerative axonal growth and lead to poor or negligible recovery of motor function (Akbik et al. 2012; Masu 2016).

Chondroitin sulphate proteoglycans (CSPGs) are amongst the key repulsive cues for axon regeneration in injured central nervous system (CNS) tissue. In the CNS, CSPGs condense around neurons soma and proximal dendrites to form perineuronal nets (PNNs), which are specialized extracellular-matrix structures that interdigitate with axonal and synaptic contacts (Ye and Miao 2013). PNNs are implicated in the termination of critical periods during development, as well in impeding axonal regeneration and synaptic plasticity in adulthood (Beurdeley et al. 2012; Sorg et al. 2016; Banerjee et al. 2017). The chondroitinsulfate glycosaminoglycan side chains (CS moieties) of CSPGs are responsible for PNN formation and control the critical periods for plasticity of multiple circuits (Bradbury et al. 2002; Pizzorusso et al. 2002; Hou et al. 2017; Sullivan et al. 2018; Fawcett et al. 2019). The CS moieties are complex unbranched polysaccharides of variable length with a backbone structure composed of a repeating disaccharide unit consisting of D-glucuronic acid (GlcA) and N-acetyl-D-galactosamine (GalNAc) (Yutsudo and Kitagawa 
2015). This simple repetitive structure can then undergo extensive modification by sulfation at the $\mathrm{C} 4$ or C6 position of GalNAc residues during biosynthesis. During biosynthesis, individual GalNAc residues of the repeated disaccharide units can be sulfated at $\mathrm{C} 6$ or $\mathrm{C} 4$ by chondroitin $6-0$-sulfotransferase-1 (C6ST1) and chondroitin 4-0-sulfotransferase-1 (C4ST-1), respectively (Mikami et al. 2003). Previous studies have found that changes in the activities of C6ST-1/C4ST-1 induce developmental increases/decreases in the 4-sulfation/6-sulfation ratio of CSPGs during development and in several CNS diseases (Miyata et al. 2012). However, it remains largely unknown whether changes in specific sulfation patterns regulates axonal plasticity.

Following CNS disease and injuries, high levels of CSPGs are found proximal to the lesion and form distinct PNNs (Brown et al. 2012), among which CS-A (chondroitin-4-sulfation)-enriched PNNs and CS-C (chondroitin-6-sulfation)-enriched PNNs exhibit different degrees of upregulated expression. CS-Aenriched PNNs can be labeled with Wisteria floribunda agglutinin (WFA), whereas CS-C-enriched PNNs can be labeled with a CS56 antibody (Miyata and Kitagawa 2015). Previous studies have demonstrated that elimination of CSPGs with chondroitinase ABC induces neuroprotective effects (Lee et al. 2010). However, recent axon regeneration studies, utilized rodents model, have suggested that CS moieties can act as growth factor or inhibitory molecules hinging on their sulfation status (Miyata et al. 2012; Yutsudo and Kitagawa 2015). Moreover, a recent study demonstrated that knocking out CSPGs exacerbates tissue loss, inflammation and neurologic deficits after brain injury (Schafer and Tegeder 2018). The importance of specific sulfation patterns of CS moieties to axonal regeneration might have been overlooked in previous studies because chondroitinase-ABC treatment destroys all CS moieties.

Recently, single-dose X-irradiation shown potential in the amelioration of functional deficits caused by SCl in rodents (Ridet et al., 2000; Azria et al., 2012; Kim et al., 2013; LeRoux et al., 2014). A continual administration of low-dose fractionated irradiation (LDI) treatment could show a more pronounced blocking effect on the dynamic glial reaction than the single-dose treatment. Our previous beagle dogs $\mathrm{SCl}$ study also showed that LDI promoted axonal regeneration through inhibiting CSPG production (Zhang et al. 2017). However, the relationship between sulfation patterns of CS moieties and axonal regeneration has still not been addressed.

The effect of LDI treatment on functional receptors of CSPGs and 5-HT receptors also need to be clarified. CSPGs work with their receptors, Nogo receptors and leukocyte common antigen-related receptor protein tyrosine phosphatases (LAR-RPTPs), initiated promoted/inhibitory effects on axonal growth and guidance (Tran et al. 2018). Interactions of CSPGs with RPTPo or LAR have been shown in modulation of axonal regeneration and dendritic-spine formation through ADAM10 shedding, RhoA activation and tropomyosin-related kinases dephosphorylation (Kurihara and Yamashita 2012; Dyck et al. 2015; Lang et al. 2015; Fisher et al. 2011). High-affinity binding between CSPGs with NgR1/3 also has been demonstrated, knockout of $\mathrm{NgR1}$ and $\mathrm{NgR3}$ significantly promoted mice axonal regeneration following injury (Dickendesher et al. 2012). Loss of descending 5-hydroxytryptaminergic nerve fiber was involved in locomotor impairment in rodents, 5-HT receptors (including 5-HT2c/a and 5-HT7 receptors) expression are also important for locomotion recovery modulation following SCI (Slawinska et al. 2014). 
Thus, we hypothesized that sulfation patterns of CS moieties are relevant to axonal regeneration because of their putative influence on the formation of specific CS-enriched PNNs. To test this hypothesis, utilized beagle dog $\mathrm{SCl}$ model, we examined CS moieties sulfation patterns and PNN formation proximal to the lesion. Additionally, we aimed to clarify whether or not there is a change in the expression levels of CSPG receptors following $\mathrm{SCl}$ and, if so, whether and which receptors affect axonal regeneration. Finally, we investigated whether the neuroprotective effects of LDI treatment are mediated via alterations of sulfation patterns that influence PNN formation. Previous studies on spinal cord injury were more based on rodent models, but, due to the anatomical, molecular and functional differences, these findings cannot be made in humans directly. CSPGs have been studied, and chondroitinase used, in several large animal models of spinal cord injury including dog, cat, and non-human primate (Tester and Howland 2008; Jefferson et al. 2011; Muir et al. 2019; Doperalski et al. 2020). Large animal may more useful for developing therapeutic strategies in humans, and canine $\mathrm{SCl}$ model might be considered as intermediate between rodent study and human clinical trials.

\section{Experimental Procedures}

\section{Animals and surgery}

This study was carried out in accordance with the recommendations of the National Institute of Health Guide for the Care and Use of Laboratory Animals (NIH Publications No. 80 - 23) revised 1996. The procedures were performed on the animals in accordance with protocols approved (TJA-2019015) by the Institutional Animal Care and Use Committee of Tongji Hospital, Tongji Medical College, Huazhong University of Science and Technology. All surgery was performed under anesthesia with pentobarbital and isoflurane, and all efforts were made to minimize the number of animals used and their suffering.

According to the principle of completely random, adult beagle dogs $(n=30,18.5-22.0 \mathrm{~kg})$ were divided into the sham-operated group (Two time points, the number of animals at each time point $=5$ ), $\mathrm{SCl}$ group (Two time points, the number of animals at each time point $=5$ ), LDI groups (Two time points, the number of animals at each time point $=5$ ). The sample size was determined as our previous study, in particular, the sample size was calculated by PASS 15 (power $=0.90$, alpha $=0.05, G=3$, inputted mean and SEMs and calculated the sample size). All dogs were anesthetized with $35 \mathrm{mg} / \mathrm{kg}$ of pentobarbital, maintained with 1-2\% isoflurane, as described previously (Koshman et al. 2018; Goya et al. 2018). All operations were performed by the same spine surgeon who were blinded to the study. Under aseptic conditions, the laminectomy exposed the spinal cord at T9-T10 vertebral level. In the sham-operated group, only the laminectomy was performed without any other operation. In the animals of SCl group and LDI group, a tiny incision was made, the overlying meninges were slit, one micro guide wire was placed on the longitudinal axis of the spinal cord to avoid the injury of the contralateral tissue by the scalpel, and the left hemi-cord was completely transected. Following the operation completed, the incision was immediately covered with a piece of Durafilm (American Durafilm Company Inc, USA), and gelfoam filled the tissue loss dued to the laminectomy. The overlying muscles and skin were then sutured. All these consistent operations were to avoid lesion variability within or across groups of animals. 
Food and water intake of the dogs were monitored during the study. Animals recovered from surgery in a warm and comfortable room, and were returned to their quarters, penicillin were administered to prevent infection, a balanced diet including plenty of proteins was gave to the dogs, dogs' bladders were expressed 2-3 times daily until urinary incontinence disappeared. The skin also was kept clean and free of body fluids,cages were kept with very soft blankets to avoid excessive pressure and tannic acid was applied to prevent pressure ulcer.

In the LDI group, LDI program was conducted starting at 1 day post-injury and continuous conducted for 14 days. No LDI was conducted in the sham-operated and SCl group. First, modified Tarlov-grading scores for locomotor function were carried at days 1, 14 and 60 post-injury, and then all dogs were euthanized with an excessive dose of barbiturates $(100 \mathrm{mg} / \mathrm{kg})$ at 14-days $(n=5)$ and 60-days $(n=5)$ post-SCl, and samples of spinal cord were quickly removed on ice for further research. The samples were equally divided into two parts along the longitudinal axis of the spinal cord, half of the samples were used for morphological analysis and half for Western blot analysis.

\section{Low-dose-fractionated irradiation therapy}

Irradiation was delivered by an X-ray generator with a dose rate of $101.7 \mathrm{cGy} / \mathrm{min}$, a hybrid orthovoltage unit operating at $250 \mathrm{kVp}, 10 \mathrm{~mA}$ with $0.25 \mathrm{~mm}$ Cu filtration, and delivered at a distance of $50 \mathrm{~cm}$ from the dogs' skin. The exposure field was $30 \mathrm{~mm} \times 15 \mathrm{~mm}$ (length $\times$ width), and the inner boundary was the spinal cord. Previous studies showed that, for human spinal cord, the clinical-tolerance-dose values are 45-50 Gy and 33 Gy when delivered in daily fractions of $2 \mathrm{~Gy}$ and $3 \mathrm{~Gy}$, respectively (Marcus and Million 1990; Schultheiss 1990; Khan et al. 1999). In the present study, the total and fractional doses of radiotherapy were determined based on these previous studies and our previous study (Zhang et al. 2017). The LDI protocol was: LDI was performed beginning at 1-day post-SCl, and the irradiation was performed once a day for 14 days, each fractionated dose was $2 \mathrm{~Gy}$, the total dose was $28 \mathrm{~Gy}$ across 14 fractions.

\section{Immunohistochemistry}

Briefly, samples of spinal cord were quickly removed from the vertebral column on ice, fixed with $4 \%$ paraformaldehyde overnight, washed thrice in $0.1 \mathrm{M}$ PBS, immersed in $30 \%$ sucrose solution until samples sank. The optimum cutting temperature compound (Sakura, USA) then blocked the spinal cord samples. The samples were sectioned at a thickness of $40 \mu \mathrm{m}$ on a sliding microtome (CM1900, Leica, Germany). The sections were then rinsed thrice with $0.1 \mathrm{M}$ PBS, incubated with $0.2 \%$ Triton X-100 containing $1 \%$ bovine serum albumin (BSA) for $2 \mathrm{~h}$, washed thrice in PBS. The sections were incubated overnight at $4^{\circ} \mathrm{C}$ with the primary antibodies (Table 1). Longitudinal section (cut along the longitudinal axis of the spinal cord) were stained for MAP-2/5-HT, GFAP and CSPGs specific antibodies to identify the axon regeneration mecyhanism. Sagittal sections through the lesion were stained for MAP-2 and CSPG receptors antibodies to identify the result of LDI treatment on CSPGs-CSPGs receptors binding activity. The sections were washed thrice with PBS, incubated with AffiniPure donkey anti-mouse fluorescein isothiocyanate (FITC)-conjugated secondary antibodies (1:200; Code number: 715-095-150, Jackson 
ImmunoResearch), AffiniPure donkey anti-rabbit cyanine3 (Cy3)-conjugated secondary antibodies (1:200; Code number: 711-165-152, Jackson ImmunoResearch), AffiniPure donkey anti-goat cyanine3 (Су3)conjugated secondary antibodies (1:200; Code number: 705-165-003, Jackson ImmunoResearch), for 60 min at room temperature. Instead of the primary antibodies, nonspecific IgG was used for negative controls.

After tissue clearing, sections were imaged by a laser scanning confocal microscope (FV1000, Olympus, Japan). Images quantification was performed by two independent observers using Image J software. To quantify CSA/CSC and MAP-2 (+) neuron/axon density at injury site in sham-operated, SCI and LDI treatment group, CSA/CSC and MAP-2 immunoreactivities were determined by thresholding above background level. 15 slices per animal were used for quantification. To quantify the number of MAP-2 (+) or 5-HT (+) neuron/axons, $50 \mu \mathrm{m}$ square grids were generated over the entire image, every 6th square was quantified, only MAP-2 (+) or 5-HT (+) signal that is linear, at least $1 \mu \mathrm{m}$ in length was identified as one axon. For quantification of positive cell percentage, cells touching the left side line and bottom line of a square were disregarded.

\section{Western blotting}

To investigate C4ST-1 protein expressions, tissue samples (20 mm length centered at the injury site) were harvested, homogenized in lysis buffer (0.1-M NaCl; 0.01-M Tris-HCl at a pH of 7.5; 1-mM EDTA; 1-mM PMSF; and $1 \mathrm{mg} / \mathrm{mL}$ of aprotinin), centrifuged at $12,000 \mathrm{~g}\left(15 \mathrm{~min}\right.$ at $\left.4^{\circ} \mathrm{C}\right)$. Sodium dodecyl sulfate (SDS)-polyacrylamide gel electrophoresis (PAGE) was utilized to analyze protein extracts (20-100 $\mathrm{mg} / \mathrm{lane}$ ). Protein was then transferred from the gel to nitrocellulose membranes after electrophoresis. The nitrocellulose membranes were blocked with $5 \%$ non-fat milk solution in TBS- $0.1 \%$ Tween, incubated with anti-C4ST-1 (1:200) antibody overnight at $4^{\circ} \mathrm{C}$. The anti- $\beta$-actin antibody $(1: 5,000$, Neomarkers, CA) was blotted to confirm equal protein loading. After incubated with peroxidase-linked secondary antibody for $2 \mathrm{~h}$ in room temperature, C4ST-1 protein was visualized using an enhanced chemiluminescent system (Supersignal West Pico Trial Kit, 34577, Pierce, CA). The specificity of antibodies was compared between rat spinal cord samples and canine spinal cord samples, the western blot results showed that the response of the rat and canine samples to the antibody was similar (Supplement.1). For quantitative analysis, the protein bands intensity was analyzed by densitometry using the Molecular Analyst software.

\section{Three-dimensional image acquisition and reconstruction}

Three-dimensional image acquisition and reconstruction were performed as previously described (Zhang et al. 1999). Briefly, vibratome sections were incubated with the CS-56 antibody (1:100, Sigma-Aldrich) or Biotinylated WFA lectin (Vector laboratories, CA, USA) for three days at $4^{\circ} \mathrm{C}$, and then incubated with Cy3conjugated secondary antibodies (1:200, Jackson ImmunoResearch) or Alexa 488/594 conjugated streptavidin. These vibratome sections were then incubated with the $5-\mathrm{HT}$ antibody (1:100, ImmunoStar) at $4^{\circ} \mathrm{C}$ for three days, and then incubated with FITC-conjugated secondary antibodies (1:200, Jackson ImmunoResearch). The sections were analyzed with an Olympus FV1500 confocal-imaging system. Microscopic data were acquired with a $40 \mathrm{X}$ objective lens with a numerical aperture. The red (Cy3) and 
green (FITC) fluorochromes in the sections were excited by a laser beam at568 nm and $488 \mathrm{~nm}$, and the emissions were acquired with two separate photomultiplier tubes through 585-nm and 522-nm emission filters, respectively. High-resolution images from the areas located in the 10X objective were acquired with 40 thin optical sections along the z-axis with a 1- $\mu \mathrm{m}$ step size using a $40 \mathrm{X}$ objective lens. The tissue volume size was $260.6 \mu \mathrm{m} \times 260.6 \mu \mathrm{m} \times 40 \mu \mathrm{m}$. A total of 64 images were acquired from nonoverlapping fields. A single composite three-dimensional image was reconstructed using Olympus FV5700 image-analysis software. To quantify PNNs/axon in tissue samples, all CS-56/WFA-positive or 5HT-positive images acquired from the LSCM were analyzed with the FV5700 image-analysis software. Briefly, the single composite three-dimensional image dimensions given above were reconstructed from the distribution of CS-56/WFA or 5-HT immunostaining. After the volume was thresholded by a gray level of 120, three-dimensional objects were determined from the remaining voxels. A voxel was included in an object if a face, side, edge, or corner touched any voxel already in that object. The size of a threedimensional object was the number of voxels contained in the object. All three-dimensional objects with fewer than two voxels were eliminated from further analysis. The total volume of CS-56/WFA or 5-HT staining present in the rendered cube of tissue was then calculated in $\mathrm{mm}^{3}$ and was divided by the total tissue volume to determine the percentage of tissue volume that was fluorescently marked. 15 slices per animal were used for quantification.

\section{Neurologic-function scores}

Motor function was evaluated with the modified Tarlov-grading system to study the effect of LDI treatment (Rabinowitz et al. 2008). Before the surgery, the animals were trained for one week, and baseline scores were first established prior to SCl. Open-field locomotor testing was performed by two examiners, who were blinded to the study, at 1, 3, 7, 14, 30 and 60 days post-injury post-SCl using the following five-point modified Tarlov-grading system, as previously described(Rabinowitz et al. 2008): 1 flaccid hind limbs; 2 - purposeful hind-limb motion; 3 - stands unassisted; 4 - full ambulation; and 5 climbs at a $20^{\circ}$ incline. Each dog was monitored from the ipsilateral side and back for a minimum of 10 walking steps. Dogs that could not bear weight on their pelvic limbs were also recorded when supported by holding the base of their tail to allow non-weight-bearing voluntary movements of their pelvic limbs to be seen. All open-field locomotor testing was performed under the same conditions and the same time period on each scheduled testing date.

\section{Statistical analysis}

All the data were expressed as the means \pm SEMs, and analyzed using the SPSS 11.0 statistical software. Normality was counted by Shapiro-Wilk test and Kolmogorov-Smirnov test, variance homogeneity was counted by Levene's Test (see supplemental 1). Statistical analysis was evaluated by one-way analysis of variance (ANOVA) followed by Tukey's post-hoc test or repeated measures ANOVA with GreenhouseGeisser adjustment. Differences were considered statistically significant at $P<0.05$.

\section{Results}


The temporal expression and cellular localization of CS-A and CS-C proximal to the lesion following SCI.

In the present study, we first examined the expression of CS-A and CS-C moiety of CSPGs proximal to the lesion following $\mathrm{SCl}$ via immunofluorescent staining. Compared to very low levels of reactivity for CS-A in the sham-operated group, we found immediately increased staining for CS-A proximal to the lesion at 1day post-SCI that reached a peak at 14-days post-SCI. Moreover, upregulated CS-A was detected far out as 60-days post-SCI. Next, we found that LDI treatment restored the expression of CS-A to a level near that of the sham-operated group (Fig. 1A). Immunohistochemical analysis showed that, at 1-day post-SCl, $6.0 \pm 1.33$ cells $/ \mathrm{cm}^{2}$ were immunoreactive for CS-A in the sham-operated group, which increased to 16.3 $\pm 2.78 \mathrm{cells} / \mathrm{cm}^{2}$ in the SCl group and was attenuated to $10.02 \pm 0.98 \mathrm{cells} / \mathrm{cm}^{2}$ after LDI treatment ( $F(2$, 12) $=7.12, p=0.009$ ). At 14-days post-SCl, the CS-A expression level was $6.2 \pm 1.58 \mathrm{cells} / \mathrm{cm}^{2}$ in the sham-operated group, which was increased to $32.7 \pm 5.35 \mathrm{cells} / \mathrm{cm}^{2}$ in SCl group and was attenuated to $15.3 \pm 2.19$ cells $/ \mathrm{cm}^{2}$ after LDI treatment $(F(2,12)=7.39, \mathrm{p}=0.008)$.

The temporal expression of CS-C was different from that of CS-A. Our results demonstrated that no significant variation in CS-C expression was found among the sham-operated, SCI and LDI treatment groups at 1-day post-SCl. However, CS-C was increased by 14-days post-SCl and reached a peak by 60days post-SCI. Strikingly, in contrast to the results of CS-A expression, LDI treatment showed no inhibitory effect on CS-C expression following SCI (Fig. 1B). Immunohistochemical analysis showed that $5.8 \pm 2.23$ cells $/ \mathrm{cm}^{2}$ were immunoreactive for CS-C in the sham-operated group, which increased to $13.3 \pm 3.27$ cells $/ \mathrm{cm}^{2}$ at 14 -days post-SCl in the $\mathrm{SCl}$ group and was similarly $12.1 \pm 1.88 \mathrm{cells} / \mathrm{cm}^{2}$ after LDI treatment $(F(2,12)=7.59, p=0.007)$. At a later time point, there were $6.1 \pm 1.09 \mathrm{cells} / \mathrm{cm}^{2}$ in the shamoperated group, which was increased to $35.38 \pm 2.29 \mathrm{cells} / \mathrm{cm}^{2}$ at 60 -days post-SCl in SCl group and was similarly $33.51 \pm 1.97$ cells $/ \mathrm{cm}^{2}$ after LDI treatment $(F(2,12)=7.62, p=0.007)$.

We next determined the spatial expression of CS-A and CS-C proximal to the lesion. Doubleimmunofluorescent staining was performed with the following specific antibodies at the time points when CS-A and CS-C expressions reached their corresponding peaks: GFAP for astrocytes; MAP-2 for neurons and axons; LY111 for CS-A; and MC21 for CS-C. At 14-days post-SCl, we found substantial staining for CS-A proximal to the lesion, and colocalization of CS-A and GFAP was also apparent. On the contrary, a thin expression of CS-A was observed in MAP-2 positive neurons/axons (Fig. 1C). At 14-days post-SCl, the percentage of CS-A-positive astrocytes was $8.7 \pm 0.93 \%$ in the sham-operated group, which increased to $26.8 \pm 2.09 \%$ after SCI $(F(1,8)=12.81, p=0.000)$; the percentage of CS-A-positive neurons/axons was $5.5 \pm 0.86 \%$ in the sham-operated group, which was similarly $5.8 \pm 0.79 \%$ after SCl (F $(1,8)=1.25, p=0.100)$. At 60 -days post-SCI, CS-C was upregulated in both astrocytes and neurons/axons proximal to the lesion. The percentage of CS-C positive astrocytes was $5.5 \pm 0.73 \%$ in the sham-operated group, which increased to $12.2 \pm 1.29 \%$ after $\operatorname{SCl}(F(1,8)=10.82, p=0.000)$; the percentage of CS-C positive neurons/axons was $7.5 \pm 1.29 \%$ in the sham-operated group, which was increased to $39.8 \pm$ $1.28 \%$ after $\operatorname{SCl}(F(1,8)=1.35, p=0.118)$. 


\section{LDI decreases astrocyte-associated CS-A expression, restrains CS-A-enriched PNN accumulation.}

We had demonstrated that LDI inhibited CS-A expression, but not CS-C expression, proximal to the lesion following SCl. However, since CS-A is expressed in both astrocytes and neurons, we next explored whether LDI inhibits neuron-associated CS-A expression and/or astrocyte-associated CS-A expression at 14-days and 60-days post-SCI. There were rare CS-A positive neuron/axon in the sham-operated and $\mathrm{SCl}$ animals. LDI treatment did not alter CS-A expression in neuron/axon. At 14-days post-SCI, $3.2 \pm 0.38 \%$ of neuron/axon were CS-A positive in the sham-operated group, which was similarly $3.7 \pm 0.35 \%$ in the SCl group and $3.3 \pm 0.02 \%$ after $L D I$ treatment $(F(2,12)=1.55, p=0.252)$. At 60 -days post-SCl, $3.5 \pm 0.17 \%$ of neuron/axon were CS-A positive in the sham-operated group, which was similarly $3.8 \pm 0.25 \%$ in the SCl group and $3.6 \pm 0.55 \%$ after $L D I$ treatment $(F(2,12)=1.62, p=0.238)$ (Fig. 2B). In contrast, LDI treatment significantly inhibited CS-A expression in astrocytes. At 14-days post-SCI $1.2 \pm 0.58 \%$ of astrocytes were CS-A positive in the sham-operated group, which increased to $35.3 \pm 3.26 \%$ in the SCl group and was attenuated to $5.1 \pm 0.91 \%$ after $\mathrm{LDI}$ treatment $(F(2,12)=7.99, \mathrm{p}=\mathbf{0 . 0 0 6})$. At 60 -days post-SCl, $1.5 \pm 0.61 \%$ of astrocytes were CS-A positive in the sham-operated group, which increased to $39.8 \pm 2.15 \%$ in the SCI group and was attenuated to $6.3 \pm 1.03 \%$ after $L D I$ treatment $(F(2,12)=7.85, p=0.007)$ (Fig. 2A). These results revealed that $\mathrm{SCl}$ increased astrocytic but not neuronal CS-A expression, and that LDI treatment induced significant inhibition of the aberrantly elevated astrocytic CS-A expression following $\mathrm{SCl}$, but did not significantly affect the already stable neuronal CS-A expression in neurons following SCl.

We further used double-immunofluorescent staining and Western blotting to examine whether protein expression of C4ST-1 changed in the spinal cord tissue proximal to the lesion after LDI treatment. C4ST-1 expression was significantly increased in astrocytes following $\mathrm{SCl}$ in the spinal cord tissue proximal to the lesion compared to a time-matched sham-operated group (Fig. 2C) (see supplemental 2). Interestingly, after LDI treatment, C4ST-1 expression in astrocytes was significantly reduced to a level close to that of the sham-operated group. Additionally, double-immunofluorescent staining showed that $7.0 \pm 0.78 \%$ of astrocytes were C4ST-1 positive in the sham-operated group, which increased to $20.5 \pm 2.37 \%$ in the SCl group and was attenuated to $9.12 \pm 0.56 \%$ after LDI treatment at 14 -days post-SCI $(F(2,12)=8.01, p=$ 0.006). Later, at 60 -days post-SCI, $7.2 \pm 0.83 \%$ of astrocytes were C4ST-1 positive in the sham-operated group, which was increased to $19.5 \pm 1.17 \%$ in $\mathrm{SCl}$ group and was attenuated to $9.06 \pm 0.88 \%$ after LDI treatment $(F(2,12)=7.89, p=0.006)$. Complementing these results, Western blotting showed that, in the $\mathrm{SCl}$ group, the protein expression of C4ST-1 increased to $213.5 \pm 7.36 \%$ (14-days post-SCI) and $153.9 \pm$ $5.61 \%$ (60-days post-SCI) compared to those of time-matched sham-operated animals, and LDI treatment restored the C4ST-1 protein expression to $136.3 \pm 3.95 \%$ (14-days post-SCI) $(\mathbf{F}(2,12)=8.06, p=0.006)$ and $120.9 \pm 7.33 \%$ (60-days post-SCI) $(F(2,12)=8.13, p=0.005)$ of that of the sham-operated levels, respectively (Fig. 2D) (see supplemental 2).

We further investigated whether LDI treatment altered CS-A or CS-C-enriched PNNs following SCI. We used WFA to label CS-A-enriched PNNs, a CS56 antibody to label CS-C-enriched PNNs, and we quantitatively analyzed the CS-A/CS-C-enriched PNNs. We found that LDI decreased CS-A-enriched PNNs proximal to the lesion following SCI (Fig. 3A). At 14-days post-SCl, $6.3 \pm 1.12 \%$ of PNNs were CS-A- 
enriched in the sham-operated group, which was increased to $29.3 \pm 3.32 \%$ in SCl group and was attenuated to $8.85 \pm 0.96 \%$ after LDI treatment $(F(2,12)=7.93, p=0.006)$. At 60 -days post-SCl, $6.7 \pm$ $1.07 \%$ of PNNs were CS-A-enriched in the sham-operated group, which was increased to $35.3 \pm 1.89 \%$ in $\mathrm{SCl}$ group and was attenuated to $9.27 \pm 1.03 \%$ after $\operatorname{LDI}$ treatment $(\mathbf{F}(\mathbf{2}, \mathbf{1 2})=7.79, \mathbf{p}=\mathbf{0 . 0 0 7})$. However, LDI treatment had no significant inhibitory effect on CS-C-enriched PNNs expression. At 14-days post-SCI, $5.8 \pm 0.89 \%$ of PNNs were CS-C-enriched in the sham-operated group, which increased to $22.5 \pm 1.28 \%$ in the $\mathrm{SCl}$ group and was $19.25 \pm 1.53 \%$ after LDI treatment $(\mathrm{F}(2,12)=1.89, \mathrm{p}=\mathbf{0 . 1 9 3})$. At 60 -days post-SCl, $6.2 \pm 1.01 \%$ of PNNs were CS-C-enriched in the sham-operated group, which increased to $31.5 \pm 1.75 \%$ in the $\mathrm{SCl}$ group and was $28.2 \pm 1.19 \%$ after $\mathrm{LDI}$ treatment $(\mathrm{F}(2,12)=1.92, \mathrm{p}=0.189)$ (Fig. 3B).

\section{LDI increases expression of 5-HT axons accompanied with reduction of CS-A-enriched PNNs}

Using laser-scanning confocal microscopy and different fluorescent probes, we measured 5-HT axonal sprouting and CS-A-enriched/CS-C-enriched PNNs accumulation by three-dimensional image acquisition and reconstruction in sham-operated, SCl and LDI groups. Three-dimensional reconstructed images showed that prominent CS-A-enriched PNNs and CS-C-enriched PNNs surrounded axons with decreased 5 -HT positive axons on the ipsilateral side following $\mathrm{SCl}$ when compared to that of the sham-operated group. LDI treatment reversed 5-HT-positive axonal spouting and decreased CS-A-enriched PNNs accumulation, but no inhibitory effect on CS-C-enriched PNNs.

We first measured the percentage of 5-HT axons/tissue and CS-A-enriched PNNs/tissue. At 14-days post$\mathrm{SCl}$, in the sham-operated group, the percentage of $5-\mathrm{HT}$ axons/tissue was $29.6 \pm 0.67 \%$, the percentage of CS-A-enriched PNNs/tissue was $6.3 \pm 1.12 \%$; in the SCl group, $5-\mathrm{HT}$ axons were repelled in a similar manner between CS-A-enriched PNNs proximal to the lesion, and the percentage of 5-HT axons/tissue was reduced to $5.1 \pm 0.79 \%$, the percentage of CS-A-enriched PNNs/tissue was $29.3 \pm 3.32 \%$; following LDI treatment, the percentage of $5-\mathrm{HT}$ axons/tissue was increased to $25.2 \pm 1.08 \%$, the percentage of CSA-enriched PNNs/tissue was $8.85 \pm 0.96 \%$ (Fig. 3). At 60-days post-SCl, decreased 5 -HT axon also accompanied with increased CS-A-enriched PNNs. In sham-operated group, the percentage of 5-HT axons/tissue was $28.3 \pm 1.05 \%$, the percentage of CS-A-enriched PNNs/tissue was $6.7 \pm 1.07 \%$; in SCl group, the percentage of $5-\mathrm{HT}$ axons/tissue was $6.5 \pm 0.82 \%$, the percentage of CS-A-enriched PNNs/tissue was $35.3 \pm 1.89 \%$; in LDI group, the percentage of $5-H T$ axons/tissue was $25.5 \pm 1.06 \%$, the percentage of CS-A-enriched PNNs/tissue was $9.27 \pm 1.03 \%$.

The percentage of 5-HT axons/tissue and CS-C-enriched PNNs/tissue were also measured. At 14-days post-SCl, in the sham-operated group, the percentage of $5-\mathrm{HT}$ axons/tissue was $27.3 \pm 0.85 \%$, the percentage of CS-C-enriched PNNs/tissue was $6.2 \pm 0.97 \%$; in the $\mathrm{SCl}$ group, the percentage of $5-\mathrm{HT}$ axons/tissue was reduced to $7.5 \pm 0.39 \%$, the percentage of CS-C-enriched PNNs/tissue was $28.1 \pm 1.15 \%$; following LDI treatment, the percentage of $5-\mathrm{HT}$ axons/tissue was increased to $10.3 \pm 1.22 \%$, the percentage of CS-C-enriched PNNs/tissue was $25.2 \pm 0.96 \%$. At 60-days post-SCl, in sham-operated group, the percentage of $5-\mathrm{HT}$ axons/tissue was $23.8 \pm 1.13 \%$, the percentage of CS-C-enriched PNNs/tissue was 
$6.6 \pm 1.10 \%$; in SCl group, the percentage of $5-\mathrm{HT}$ axons/tissue was $7.3 \pm 1.01 \%$, the percentage of CS-Cenriched PNNs/tissue was $36.3 \pm 1.77 \%$; in LDI group, the percentage of $5-\mathrm{HT}$ axons/tissue was $11.2 \pm$ $1.63 \%$, the percentage of CS-C-enriched PNNs/tissue was $32.2 \pm 0.89 \%$.

We further analyzed the correlation between of 5-HT axonal immunoreactivity and CS-A/CS-C-enriched PNNs immunoreactivity through Pearson correlation following LDI treatment. There was a significant correlation between a reduction of CS-A-enriched PNNs and an increase of 5-HT axonal immunoreactivity $\left(r^{2}=0.810\right.$ at 14 -days post-SCl, $r^{2}=0.706$ at 60 -days post-SCl, $\left.\mathrm{P}<0.05\right)$, but no significant correlation between change of CS-C-enriched PNNs and an increase of 5-HT axonal immunoreactivity $\left(r^{2}=0.050\right.$ at 14-days post-SCl, $\mathrm{r}^{2}=0.249$ at 60 -days post-SCl, $\mathrm{P}>0.05$ ).

\section{LDI increases 5-HT receptor expression but does not affect Nogo receptors, RPTPo or LAR expression following $\mathrm{SCl}$.}

In order to identify the effect of LDI treatment on functional receptors of CSPGs and 5-HT receptors, we compared the expression levels of 5-HT receptors, Nogo receptors, RPTPo and LAR in neurons through double-immunofluorescent staining in the sham, SCl and LDI groups.

As shown in Fig. 4, the sham-operated group showed a very weak expression of $5-\mathrm{HT}_{2 \mathrm{c} / \mathrm{a}}$ and $5-\mathrm{HT}_{7}$, and these expression levels were similar in the $\mathrm{SCl}$ group. In contrast, the LDI group showed a significantly increased expression of $5-\mathrm{HT}_{2 \mathrm{~A}}, 5-\mathrm{HT}_{2 \mathrm{C}}$ and $5-\mathrm{HT}_{7}$ in neurons (Fig. 4). The percentage of $5-\mathrm{HT}_{2 \mathrm{c} / \mathrm{a}}$-positive neurons was $12.5 \pm 1.08 \%$ in the sham-operated group, $18.2 \pm 2.16 \%$ in the $\mathrm{SCl}$ group, and was increased to $26.7 \pm 1.67 \%$ in the LDI group $(F(2,12)=8.65, p=0.005)$. Similarly, the percentage of $5-\mathrm{HT}_{7}$-positive neurons was $11.7 \pm 0.88 \%$ in the sham-operated group, $18.6 \pm 1.03 \%$ in the SCI group, and was increased to $27.3 \pm 1.25 \%$ in the LDI group $(F(2,12)=8.82, p=0.004)$.

We next investigated to what extent LDI could be involved in the regulation of the Nogo receptors, NgR1 and NgR3. The sham-operated group only showed minimal expression of NgR1 and NgR3 in neurons. In comparison to the sham-operated group, the $\mathrm{SCl}$ group showed an increased expression of $\mathrm{NgR} 1$ and $\mathrm{NgR3}$ in neurons. There was no significant difference in the expression of $\mathrm{NgR} 1$ or NgR3 in neurons between the $\mathrm{SCl}$ group and LDI group (Fig. 5A,C). The percentage of NgR1-positive neurons was $8.3 \pm$ $0.58 \%$ in the sham-operated group, $9.3 \pm 0.86 \%$ in the SCl group, and $9.8 \pm 0.67 \%$ in the LDI group ( $F(2$, $12)=1.58, p=0.250$ ). The percentage of $\mathrm{NgR} 3$-positive neurons was $8.5 \pm 0.63 \%$ in the sham-operated group, $9.6 \pm 0.59 \%$ in the $\mathrm{SCl}$ group, and $10.1 \pm 0.82 \%$ in the LDI group $(F(2,12)=1.32, p=0.303)$.

We also measured the expression of RPTP- $\sigma$ and LAR in neurons. Similar to the expression of NgR1 and $\mathrm{NgR} 3$, there was no significant difference in the expression of RPTP- $\sigma$ or LAR in neurons between the SCI group and LDI group (Fig. 5B, D). The percentage of RPTP- - -positive neurons was $6.8 \pm 0.56 \%$ in the sham-operated group and increased to $15.8 \pm 1.01 \%$ in the SCl group and $16.2 \pm 1.67 \%$ in the LDI group (F $(2,12)=1.01, p=0.393)$. The percentage of LAR-positive neurons was $5.9 \pm 0.63 \%$ in the sham-operated 
group and increased to $22.9 \pm 1.58 \%$ in the SCI group and $23.7 \pm 1.33 \%$ in the LDI group $(F(2,12)=0.83$, $p=0.459)$.

\section{LDI promotes motor function recovery following SCl.}

The modified-Tarlov grading system was used to test hindlimb motor-function. The motor function of the hindlimbs was intact before SCl. After SCl, the injured side lower limbs were paralysis (Tarlov Grade 1) and incontinent, which suggested a severe and consistent lesion. After injury, serious hindlimb paralysis with no residual motor function was observed in all dogs, and hindlimb scores neared zero. At 7 days post-injury, some animals regained a slight improvement for weight support due to spontaneous recovery. Compared to SCl-treated animals, enhanced hindlimb motor-function recovery occurred in the LDI-treated animals. At 14 days post-SCl, the modified Tarlov scale in the sham-operated group was 5(0); this level decreased to $3(0)$ in the $S C l$ group and was ameliorated to $3(1)$ with $\operatorname{LDI}$ treatment $(F(2,12)=10.67, p=$ 0.002); At 60 days post-SCl, the modified Tarlov scale in the sham-operated group was $5(0)$; this level decreased to $3(1)$ in the $S C l$ group and was ameliorated to $4(0)$ with $\operatorname{LDI}$ treatment $(F(2,12)=10.25, p=$ 0.002) (Fig. 6). These data suggest that LDI treatment improved hindlimb motor-function recovery after $\mathrm{SCl}$.

\section{Discussion}

In this study, we show that specific sulfation patterns of CSs moieties play different role in modulation of axon re-growth in a canine SCI model. Upregulated CS-A expression occurred at 1-day post-SCl, earlier than CS-C which was increased at 14-days post-SCI. CS-A was mainly colocalized with astrocytes but CS$C$ was upregulated in both astrocytes and neurons/axons. LDI significantly inhibited the expressions of astrocyte-associated CS-A and CS-A-enriched PNNs, but no inhibitory effect on CS-C and CS-C-enriched PNNs. There was a significant correlation between a reduction of CS-A-enriched PNNs and an increase of serotonergic (5-hydroxytryptamine, 5-HT) axonal sprouting. Increased serotonergic axon sprouting proximal to the lesion could be enhanced via $5 \mathrm{HT}$ receptor inducing following LDI treatment. Furthermore, LDI treatment promoted hindlimb motor function recovery following SCl.

Translational therapy for $\mathrm{SCl}$, from laboratory to clinic, has been highlighting the suitable animal models which mirrored human conditions. Dogs' spinal cords more closely resemble humans' than do those in rodent species, including genetic similarities, similar caliber/length of the spinal cord, similarity of biological responses to $\mathrm{SCl}$ (such as inflammatory reaction); and more human-like spontaneous recovery (Jeffery et al. 2006; Webb et al. 2004). Dogs' larger sized cord mimics the changes in human SCl, specifically in axonal sprouting across glial scars. In addition, pathophysiological investigations and neurological function examinations can be carried out easily in dog (including histopathology examination, MRI, evoked potentials, and functional outcome scores) (Jeffery et al. 2020). There are also several potential disadvantages including ethical concerns and high operating costs. Therefore, we strictly applied the principle of the 3Rs (replacement, reduction, refinement) to reduce the number of 
animals used in experiments as far as possible, to refine the pain and distress to which animals are exposed. We also explored some special methods suitable for beagle dogs postoperative care.

Previous studies have shown that CSPGs inhibit axonal regeneration. However, the importance of specific sulfation patterns of CSs moieties to axon regeneration might have been overlooked in previous studies, because some treatments, as represented by chondroitinase ABC, destroy all CSs moieties. Following CNS injury, there is a large overall increase in CS moieties, many studies shown different changes in the patterns of sulfation. Upregulation of CS-A, but not CS-C, is found in spinal cord tissue following SCI (Properzi et al. 2005; Wang et al. 2008). In contrast, CS-C and C6ST-1 (key enzymes for CS-C Synthesis) are upregulated following cortical-stab injury in the mouse cerebral cortex (Properzi et al. 2005; Yin et al. 2009; Yutsudo and Kitagawa 2015). The expression imbalance of CSs moieties around the lesion site might be a determining factor for axonal regeneration. Previous studies showed that CS-A and CS-C have different effects on plasticity, CS-C was beneficial to axon regeneration, while CS-A was inhibitory (Bhattacharyya et al. 2009; Yoo et al. 2013; Pearson et al. 2018). Our present results showed that, in beagle dogs, CS-A and CS-C moieties increased at different time points. In our present study, CS-A immediately increased, reached a peak at 14-days and still be observed at 60 -days post-SCI. In contrast, CS-C increased at 14-days and reached a peak at 60-days post-SCI. In addition, CS-A was mainly expressed in astrocytes, while CS-C was expressed in neuron/axons and astrocytes following SCl. The different temporal and spatial expressions of CSs in the CNS might offer promising therapeutic time windows or targets.

Our study further demonstrated that, after LDI treatment, astrocytes associated CS-A dramatically decreased proximal to the lesion, but this tendency was not shown in astrocytes associated CS-C, neurons associated CS-A and neurons associated CS-C in the same place. Our early administration of LDI (LDI treatment was performed beginning at 1-day post-SCI) largely inhibit the expression of astrocytes associated CS-A following SCl, potentially decreased astrocyte activation and reduced release of astrocyte associated cytokines. More important, continuous LDI intervention (the irradiation was continuous performed for 14 days) induced a durable and specific elimination during the peak period of astrocyte-associated CS-A expression. By contrast, transient intervention of CSPG often yields undesirable effects. A recent study showed that single administration of chondroitinase $A B C$ transient increased pericontusional grey and white matter sprouting in the rat cortex, but no continuous motor function recovery; the transient effects of CSPG cleavage also accompanied with the delayed CS moieties upregulation and a decline in neuroplasticity (Harris et al. 2010). LDI could inhibited astrocytes and microglia proliferation following SCl (Zhang et al. 2017). Moreover, early modulation cell-cycle of astrocytes and microglia reduced the levels of inhibitory molecules for axonal regeneration (Zhang et al. 2009; Wang et al. 2009). Therefore, the possible reason why LDI specific inhibited the CS-A and had little effect on CS-C was as follows: 1.LDI treatment inhibited astrocytes activation/proliferation following SCl, the CS-A level decreased due to reducing the number and activity of astrocytes. 2. During CS-A biosynthesis, GalNAc residues of the repeating disaccharide units are sulfated at C4 by C4ST-1, the key synthesis enzyme of CS-A. In this study, LDI inhibited the expression of C4ST-1, which led to the decrease of CS-A expression. 3. The inhibition of astrocyte activation block the secondary inflammatory reaction 
(activation/migration of microglia and macrophages, and release of a large number of inflammatory factors), which reaction further enhanced astrocytes activation/proliferation.

CSPGs recruit adhesion molecules and growth factors to their cognate receptors (Leadbeater et al. 2006). These co-receptor functions are important for axonal growth and guidance (Hacker et al. 2005), and these co-receptors (Nogo receptors and LAR-RPTPs) show different affinities to CS moieties of CSPGs. For example, $\mathrm{NgR} 1$ and $\mathrm{NgR} 3$, the Nogo receptors, showed high-affinity activity to CS-B, CS-D and CS-E (Brown et al. 2012; Mironova and Giger 2013); and RPTP $\sigma$ strongly bind with CS-D and CS-E (Yi et al. 2014). In our present study, the expression level of CSPGs receptors (Nogo-receptor, RPTPo or LAR) showed no significant difference between $\mathrm{SCl}$ and LDI group. Another kind of receptors, $5-\mathrm{HT}_{2 \mathrm{c} / \mathrm{a}}$ and 5$\mathrm{HT}_{7}$, showed increased levels in LDI treatment group. The increased $5-\mathrm{HT}_{2} \mathrm{c} / \mathrm{a}$ and $5-\mathrm{HT}_{7}$ expression might be an enhanced compensatory mechanism for serotonergic axon sprouting following LDI treatment.

The locomotion dysfunction following SCl can be attributed considerably to the loss of descending 5-HT pathways. Previous studies have also demonstrated that increased sprouting of 5-HT fibers promoted locomotor functional recovery (Tom et al. 2009; Warren et al. 2018). Promotion of 5-HT axonal regeneration after spinal cord injury might be a promising treatment. In this study, the increased expression of 5-HT axons and 5-HT receptors, in the LDI treatment group, might be the major positive factor for locomotor recovery.

Our three-dimensional image acquisition and reconstruction also showed that there was a significant correlation between a reduction of CS-A-enriched PNNs and an increase of 5-HT axonal immunoreactivity, but no correlation between change of CS-C-enriched PNNs and 5-HT axonal immunoreactivity. After SCl, some residual axons attempted to reconstruct neuron circuit. However, due to lacking of guidance mechanisms, these residual axons mostly connected to wrong targets and became dystrophic endbulbs, resulted in poor limb motor function (Hill 2017; Young 2014). By eliminating PNNs, chondroitinase ABC showed neuroplasticity and allows recovery of skilled paw-reaching functionality (Tom et al. 2009). If the downregulation of CS-A-enriched PNNs leads to an increase in CNS plasticity, we would therefore expect that LDI treatment would recover limb motor function after nerve repair. As expected, the LDI treatment animals showed efficacious recovery over the entire experimental period, indicating a high level of spinal cord plasticity.

Taken together, our findings show that specific sulfation patterns along the carbohydrate backbone of CSPGS and CSPG-enriched PNNs involved in carrying instructions for regulating axonal regeneration. LDI provided a highway for axon regeneration while inducing reinnervation of axonal targets. Therefore, LDI treatment may be an efficacious strategy for treating $\mathrm{SCl}$.

\section{Declarations}

\section{ACKNOWLEDGMENTS}


The investigations were supported by National Natural Science Foundation of China (81471230, 30900450 to Qiang Zhang, 81601480 to Ying Xiong and 91332108 to Wei Wang).We thank LetPub (www.letpub.com) for its linguistic assistance during the preparation of this manuscript.

\section{AUTHOR CONTRIBUTION}

Q.Z and W.W designed the research. Q.Z, Y.X and Bo.Z conducted the research. Y.X, J.X and Bi. Z analyzed and interpreted the data. Q.Z and Y.X wrote the manuscript.

\section{DECLARATION OF COMPETING INTEREST}

Authors confirm that they have no conflicts of interest related with the preset study.

\section{References}

1. Akbik F, Cafferty WB, Strittmatter SM (2012) Myelin associated inhibitors: a link between injuryinduced and experience-dependent plasticity. Exp Neurol 235(1):43-52. doi:10.1016/j.expneurol.2011.06.006

2. Azria D, Betz M, Bourgier C, Jeanneret Sozzi W, Ozsahin M (2012) Identifying patients at risk for late radiation-induced toxicity. Crit Rev Oncol Hematol 84 Suppl 1:e35-e41. doi:10.1016/j.critrevonc.2010.08.003

3. Banerjee SB, Gutzeit VA, Baman J, Aoued HS, Doshi NK, Liu RC, Ressler KJ (2017) Perineuronal Nets in the Adult Sensory Cortex Are Necessary for Fear Learning. Neuron 95(1):169-179 e163. doi:10.1016/j.neuron.2017.06.007

4. Beurdeley M, Spatazza J, Lee HH, Sugiyama S, Bernard C, Di Nardo AA, Hensch TK, Prochiantz A (2012) Otx2 binding to perineuronal nets persistently regulates plasticity in the mature visual cortex. J Neurosci 32(27):9429-9437. doi:10.1523/JNEUROSCI.0394-12.2012

5. Bhattacharyya S, Solakyildirim K, Zhang Z, Linhardt RJ, Tobacman JK (2009) Chloroquine reduces arylsulphatase $B$ activity and increases chondroitin-4-sulphate: implications for mechanisms of action and resistance. Malar J 8:303. doi:10.1186/1475-2875-8-303

6. Bradbury EJ, Moon LD, Popat RJ, King VR, Bennett GS, Patel PN, Fawcett JW, McMahon SB (2002) Chondroitinase ABC promotes functional recovery after spinal cord injury. Nature 416(6881):636640. doi:10.1038/416636a

7. Brown JM, Xia J, Zhuang B, Cho KS, Rogers CJ, Gama Cl, Rawat M, Tully SE, Uetani N, Mason DE, Tremblay ML, Peters EC, Habuchi O, Chen DF, Hsieh-Wilson LC (2012) A sulfated carbohydrate epitope inhibits axon regeneration after injury. Proc Natl Acad Sci U S A 109(13):4768-4773. doi:10.1073/pnas.1121318109

8. Dickendesher TL, Baldwin KT, Mironova YA, Koriyama Y, Raiker SJ, Askew KL, Wood A, Geoffroy CG, Zheng B, Liepmann CD, Katagiri Y, Benowitz LI, Geller HM, Giger RJ (2012) NgR1 and NgR3 are receptors for chondroitin sulfate proteoglycans. Nat Neurosci 15(5):703-712. doi:10.1038/nn.3070 
9. Doperalski AE, Montgomery LR, Mondello SE, Howland DR (2020) Anatomical Plasticity of Rostrally Terminating Axons as a Possible Bridging Substrate across a Spinal Injury. J Neurotrauma 37(6):877-888. doi:10.1089/neu.2018.6193

10. Dyck SM, Alizadeh A, Santhosh KT, Proulx EH, Wu CL, Karimi-Abdolrezaee S (2015) Chondroitin Sulfate Proteoglycans Negatively Modulate Spinal Cord Neural Precursor Cells by Signaling Through LAR and RPTPsigma and Modulation of the Rho/ROCK Pathway. Stem Cells 33(8):2550-2563. doi:10.1002/stem.1979

11. Fawcett JW, Oohashi T, Pizzorusso T (2019) The roles of perineuronal nets and the perinodal extracellular matrix in neuronal function. Nat Rev Neurosci 20(8):451-465. doi:10.1038/s41583-0190196-3

12. Fink KL, Lopez-Giraldez F, Kim IJ, Strittmatter SM, Cafferty WBJ (2017) Identification of Intrinsic Axon Growth Modulators for Intact CNS Neurons after Injury. Cell Rep 18(11):2687-2701. doi:10.1016/j.celrep.2017.02.058

13. Fisher D, Xing B, Dill J, Li H, Hoang HH, Zhao Z, Yang XL, Bachoo R, Cannon S, Longo FM, Sheng M, Silver J, Li S (2011) Leukocyte common antigen-related phosphatase is a functional receptor for chondroitin sulfate proteoglycan axon growth inhibitors. J Neurosci 31(40):14051-14066. doi:10.1523/JNEUROSCI.1737-11.2011

14. Goya S, Wada T, Shimada K, Hirao D, Tanaka R (2018) Dose-dependent effects of isoflurane and dobutamine on cardiovascular function in dogs with experimental mitral regurgitation. Vet Anaesth Analg 45(4):432-442. doi:10.1016/j.vaa.2018.03.010

15. Hacker U, Nybakken K, Perrimon N (2005) Heparan sulphate proteoglycans: the sweet side of development. Nat Rev Mol Cell Biol 6(7):530-541. doi:10.1038/nrm1681

16. Harris NG, Mironova YA, Hovda DA, Sutton RL (2010) Chondroitinase ABC enhances pericontusion axonal sprouting but does not confer robust improvements in behavioral recovery. J Neurotrauma 27(11):1971-1982. doi:10.1089/neu.2010.1470

17. Hill CE (2017) A view from the ending: Axonal dieback and regeneration following SCl. Neurosci Lett 652:11-24. doi:10.1016/j.neulet.2016.11.002

18. Hou X, Yoshioka N, Tsukano H, Sakai A, Miyata S, Watanabe Y, Yanagawa Y, Sakimura K, Takeuchi K, Kitagawa H, Hensch TK, Shibuki K, Igarashi M, Sugiyama S (2017) Chondroitin Sulfate Is Required for Onset and Offset of Critical Period Plasticity in Visual Cortex. Sci Rep 7(1):12646. doi:10.1038/s41598-017-04007-x

19. Jefferson SC, Tester NJ, Howland DR (2011) Chondroitinase ABC promotes recovery of adaptive limb movements and enhances axonal growth caudal to a spinal hemisection. J Neurosci 31(15):57105720. doi:10.1523/JNEUROSCI.4459-10.2011

20. Jeffery ND, Mankin JM, Ito D, Boudreau CE, Kerwin SC, Levine JM, Krasnow MS, Andruzzi MN, Alcott CJ, Granger N (2020) Extended durotomy to treat severe spinal cord injury after acute thoracolumbar disc herniation in dogs. Vet Surg. doi:10.1111/vsu.13423 
21. Jeffery ND, Smith PM, Lakatos A, Ibanez C, Ito D, Franklin RJ (2006) Clinical canine spinal cord injury provides an opportunity to examine the issues in translating laboratory techniques into practical therapy. Spinal Cord 44(10):584-593. doi:10.1038/sj.sc.3101912

22. Jeffrey PR, Nhat-Thi Vo,Alvaro Sagasti (2018) Fish Scales Dictate the Pattern of Adult Skin Innervation and Vascularization. Dev Cell 46(3):344-359.e4. doi:10.1016/j.devcel.2018.06.019

23. Jung-Yu C, Hsu,Robert McKeon,Staci Goussev,Zena Werb,Jung-Uek Lee,Alpa Trivedi,Linda J, NobleHaeusslein (2006) Matrix metalloproteinase-2 facilitates wound healing events that promote functional recovery after spinal cord injury. J Neurosci,26(39):9841-50. doi:

10.1523/JNEUROSCI.1993-06.2006

24. Khan DC, Malhotra S, Stevens RE, Steinfeld AD (1999) Radiotherapy for the treatment of giant cell tumor of the spine: a report of six cases and review of the literature. Cancer Invest 17(2):110-113

25. Kim JS, Yang M, Kim SH, Shin T, Moon C (2013) Neurobiological toxicity of radiation in hippocampal cells. Histol Histopathol 28(3):301-310. doi:10.14670/HH-28.301

26. Koshman YE, Herzberg BR, Seifert TR, Polakowski JS, Mittelstadt SW (2018) The evaluation of druginduced changes in left ventricular function in pentobarbital-anesthetized dogs. J Pharmacol Toxicol Methods 91:27-35. doi:10.1016/j.vascn.2018.01.002

27. Kurihara D, Yamashita $T$ (2012) Chondroitin sulfate proteoglycans down-regulate spine formation in cortical neurons by targeting tropomyosin-related kinase B (TrkB) protein. J Biol Chem 287(17):13822-13828. doi:10.1074/jbc.M111.314070

28. Lang BT, Cregg JM, DePaul MA, Tran AP, Xu K, Dyck SM, Madalena KM, Brown BP, Weng YL, Li S, Karimi-Abdolrezaee S, Busch SA, Shen Y, Silver J (2015) Modulation of the proteoglycan receptor PTPsigma promotes recovery after spinal cord injury. Nature 518(7539):404-408. doi:10.1038/nature13974

29. Leadbeater WE, Gonzalez AM, Logaras N, Berry M, Turnbull JE, Logan A (2006) Intracellular trafficking in neurones and glia of fibroblast growth factor-2, fibroblast growth factor receptor 1 and heparan sulphate proteoglycans in the injured adult rat cerebral cortex. J Neurochem 96(4):11891200. doi:10.1111/j.1471-4159.2005.03632.x

30. Lee H, McKeon RJ, Bellamkonda RV (2010) Sustained delivery of thermostabilized chABC enhances axonal sprouting and functional recovery after spinal cord injury. Proc Natl Acad Sci U S A 107(8):3340-3345. doi:10.1073/pnas.0905437106

31. LeRoux LG, Bredow S, Grosshans D, Schellingerhout D (2014) Molecular imaging detects impairment in the retrograde axonal transport mechanism after radiation-induced spinal cord injury. Mol Imaging Biol 16(4):504-510. doi:10.1007/s11307-013-0713-0

32. Marcus RB Jr, Million RR (1990) The incidence of myelitis after irradiation of the cervical spinal cord. Int J Radiat Oncol Biol Phys 19(1):3-8. doi:10.1016/0360-3016(90)90126-5

33. Masu M (2016) Proteoglycans and axon guidance: a new relationship between old partners. $J$ Neurochem 139 Suppl 2:58-75. doi:10.1111/jnc.13508 
34. Mattias ND, Svensson,Martina Zoccheddu,Shen Yang,Gyrid Nygaard,Christian Secchi,Karen MD,Kamil Slowikowski,Fumitaka Mizoguchi,Frances Humby,Rebecca Hands,Eugenio Santelli,Cristiano Sacchetti,Kuninobu Wakabayashi,Dennis J (2020) Synoviocyte-targeted therapy synergizes with TNF inhibition in arthritis reversal. Sci Adv,6(26):eaba4353. doi:

10.1126/sciadv.aba4353

35. Mikami T, Mizumoto S, Kago N, Kitagawa H, Sugahara K (2003) Specificities of three distinct human chondroitin/dermatan $\mathrm{N}$-acetylgalactosamine 4-O-sulfotransferases demonstrated using partially desulfated dermatan sulfate as an acceptor: implication of differential roles in dermatan sulfate biosynthesis. J Biol Chem 278(38):36115-36127. doi:10.1074/jbc.M306044200

36. Mironova YA, Giger RJ (2013) Where no synapses go: gatekeepers of circuit remodeling and synaptic strength. Trends Neurosci 36(6):363-373. doi:10.1016/j.tins.2013.04.003

37. Miyata S, Kitagawa $H(2015)$ Mechanisms for modulation of neural plasticity and axon regeneration by chondroitin sulphate. J Biochem 157(1):13-22. doi:10.1093/jb/mvu067

38. Miyata S, Komatsu Y, Yoshimura Y, Taya C, Kitagawa H (2012) Persistent cortical plasticity by upregulation of chondroitin 6-sulfation. Nat Neurosci 15(3):414-422. doi:10.1038/nn.3023 S411412.

39. Muir E, De Winter F, Verhaagen J, Fawcett J (2019) Recent advances in the therapeutic uses of chondroitinase ABC. Exp Neurol 321:113032. doi:10.1016/j.expneurol.2019.113032

40. O'Shea TM, Burda JE, Sofroniew MV (2017) Cell biology of spinal cord injury and repair. J Clin Invest 127(9):3259-3270. doi:10.1172/JCI90608

41. Pearson CS, Mencio CP, Barber AC, Martin KR, Geller HM (2018) Identification of a critical sulfation in chondroitin that inhibits axonal regeneration. Elife 7. doi:10.7554/eLife.37139

42. Philippa M, Warren,Stephanie C, Steiger,Thomas E, Dick,Peter M, MacFarlane,Warren JA, Jerry Silver (2018) Rapid and robust restoration of breathing long after spinal cord injury. Nat Commun 9(1):4843. doi:10.1038/s41467-018-06937-0

43. Pizzorusso T, Medini P, Berardi N, Chierzi S, Fawcett JW, Maffei L (2002) Reactivation of ocular dominance plasticity in the adult visual cortex. Science 298(5596):1248-1251. doi:10.1126/science.1072699

44. Properzi F, Carulli D, Asher RA, Muir E, Camargo LM, van Kuppevelt TH, ten Dam GB, Furukawa Y, Mikami T, Sugahara K, Toida T, Geller HM, Fawcett JW (2005) Chondroitin 6-sulphate synthesis is upregulated in injured CNS, induced by injury-related cytokines and enhanced in axon-growth inhibitory glia. Eur J Neurosci 21(2):378-390. doi:10.1111/j.1460-9568.2005.03876.x

45. Rabinowitz RS, Eck JC, Harper CM Jr, Larson DR, Jimenez MA, Parisi JE, Friedman JA, Yaszemski MJ, Currier BL (2008) Urgent surgical decompression compared to methylprednisolone for the treatment of acute spinal cord injury: a randomized prospective study in beagle dogs. Spine (Phila Pa 1976) 33(21):2260-2268. doi:10.1097/BRS.0b013e31818786db

46. Ridet JL, Pencalet P, Belcram M, Giraudeau B, Chastang C, Philippon J, Mallet J, Privat A, Schwartz L (2000) Effects of spinal cord X-irradiation on the recovery of paraplegic rats. Exp Neurol 161(1):1- 


\section{4. doi:10.1006/exnr.1999.7206}

47. Schafer MKE, Tegeder I (2018) NG2/CSPG4 and progranulin in the posttraumatic glial scar. Matrix Biol 68-69:571-588. doi:10.1016/j.matbio.2017.10.002

48. Schultheiss TE (1990) Spinal cord radiation "tolerance": doctrine versus data. Int J Radiat Oncol Biol Phys 19(1):219-221. doi:10.1016/0360-3016(90)90157-f

49. Sharma R, Al-Saleem FH, Panzer J, Lee J, Puligedda RD, Felicori LF, Kattala CD, Rattelle AJ, Ippolito G, Cox RH, Lynch DR, Dessain SK (2018) Monoclonal antibodies from a patient with anti-NMDA receptor encephalitis. Ann Clin Transl Neurol 5(8):935-951. doi:10.1002/acn3.592

50. Slawinska U, Miazga K, Jordan LM (2014) The role of serotonin in the control of locomotor movements and strategies for restoring locomotion after spinal cord injury. Acta Neurobiol Exp (Wars) 74(2):172-187

51. Raha-Chowdhury,James SFoscarin,Ruma, Fawcett,Jessica W, Kwok CF (2017) Brain ageing changes proteoglycan sulfation, rendering perineuronal nets more inhibitory. Aging 9(6):1607-1622. doi:10.18632/aging.101256

52. Sorg BA, Berretta S, Blacktop JM, Fawcett JW, Kitagawa H, Kwok JC, Miquel M (2016) Casting a Wide Net: Role of Perineuronal Nets in Neural Plasticity. J Neurosci 36(45):11459-11468. doi:10.1523/JNEUROSCI.2351-16.2016

53. Sullivan CS, Gotthard I, Wyatt EV, Bongu S, Mohan V, Weinberg RJ, Maness PF (2018) Perineuronal Net Protein Neurocan Inhibits NCAM/EphA3 Repellent Signaling in GABAergic Interneurons. Sci Rep 8(1):6143. doi:10.1038/s41598-018-24272-8

54. Tester NJ, Howland DR (2008) Chondroitinase ABC improves basic and skilled locomotion in spinal cord injured cats. Exp Neurol 209(2):483-496. doi:10.1016/j.expneurol.2007.07.019

55. Tohda C, Kuboyama T (2011) Current and future therapeutic strategies for functional repair of spinal cord injury. Pharmacol Ther 132(1):57-71. doi:10.1016/j.pharmthera.2011.05.006

56. Tom VJ, Kadakia R, Santi L, Houle JD (2009) Administration of chondroitinase ABC rostral or caudal to a spinal cord injury site promotes anatomical but not functional plasticity. J Neurotrauma 26(12):2323-2333. doi:10.1089/neu.2009.1047

57. Tran AP, Warren PM, Silver J (2018) The Biology of Regeneration Failure and Success After Spinal Cord Injury. Physiol Rev 98(2):881-917. doi:10.1152/physrev.00017.2017

58. Wang H, Katagiri Y, McCann TE, Unsworth E, Goldsmith P, Yu ZX, Tan F, Santiago L, Mills EM, Wang Y, Symes AJ, Geller HM (2008) Chondroitin-4-sulfation negatively regulates axonal guidance and growth. J Cell Sci 121(Pt 18):3083-3091. doi:10.1242/jcs.032649

59. Wang W, Bu B, Xie M, Zhang M, Yu Z, Tao D (2009) Neural cell cycle dysregulation and central nervous system diseases. Prog Neurobiol 89(1):1-17. doi:10.1016/j.pneurobio.2009.01.007

60. Warren PM, Steiger SC, Dick TE, MacFarlane PM, Alilain WJ, Silver J (2018) Rapid and robust restoration of breathing long after spinal cord injury. Nat Commun 9(1):4843. doi:10.1038/s41467018-06937-0 
61. Webb AA, Jeffery ND, Olby NJ, Muir GD (2004) Behavioural analysis of the efficacy of treatments for injuries to the spinal cord in animals. Vet Rec 155(8):225-230. doi:10.1136/vr.155.8.225

62. Ye Q, Miao QL (2013) Experience-dependent development of perineuronal nets and chondroitin sulfate proteoglycan receptors in mouse visual cortex. Matrix Biol 32(6):352-363. doi:10.1016/j.matbio.2013.04.001

63. Yi JH, Katagiri Y, Yu P, Lourie J, Bangayan NJ, Symes AJ, Geller HM (2014) Receptor protein tyrosine phosphatase sigma binds to neurons in the adult mouse brain. Exp Neurol 255:12-18. doi:10.1016/j.expneurol.2014.02.007

64. Yin J, Sakamoto K, Zhang H, Ito Z, Imagama S, Kishida S, Natori T, Sawada M, Matsuyama Y, Kadomatsu K (2009) Transforming growth factor-beta1 upregulates keratan sulfate and chondroitin sulfate biosynthesis in microglias after brain injury. Brain Res 1263:10-22.

doi:10.1016/j.brainres.2009.01.042

65. Yoo M, Khaled M, Gibbs KM, Kim J, Kowalewski B, Dierks T, Schachner M (2013) Arylsulfatase B improves locomotor function after mouse spinal cord injury. PLoS One 8(3):e57415. doi:10.1371/journal.pone.0057415

66. Young W (2014) Spinal cord regeneration. Cell Transplant 23(4-5):573-611. doi:10.3727/096368914X678427

67. Yutsudo N, Kitagawa H (2015) Involvement of chondroitin 6-sulfation in temporal lobe epilepsy. Exp Neurol 274 (Pt B):126-133. doi:10.1016/j.expneurol.2015.07.009

68. Zhang Q, Chen C, Lu J, Xie M, Pan D, Luo X, Yu Z, Dong Q, Wang W (2009) Cell cycle inhibition attenuates microglial proliferation and production of IL-1beta, MIP-1alpha, and NO after focal cerebral ischemia in the rat. Glia 57(8):908-920. doi:10.1002/glia.20816

69. Zhang Q, Xiong Y, Zhu B, Zhu B, Tian D, Wang W (2017) Low-dose fractionated irradiation promotes axonal regeneration beyond reactive gliosis and facilitates locomotor function recovery after spinal cord injury in beagle dogs. Eur J Neurosci 46(9):2507-2518. doi:10.1111/ejn.13714

70. Zhang ZG, Bower L, Zhang RL, Chen S, Windham JP, Chopp M (1999) Three-dimensional measurement of cerebral microvascular plasma perfusion, glial fibrillary acidic protein and microtubule associated protein- 2 immunoreactivity after embolic stroke in rats: a double fluorescent labeled laser-scanning confocal microscopic study. Brain Res 844(1-2):55-66. doi:10.1016/s00068993(99)01886-7

\section{Tables}

Table.1 Primary antibody used in double-immunofluorescent staining 


\begin{tabular}{|c|c|c|c|c|c|}
\hline & Manufacturer & Clonality & $\begin{array}{l}\text { Product code } \\
\text { (Catalogue } \\
\text { number) }\end{array}$ & Dilution & Reference \\
\hline $\begin{array}{l}\text { anti- } \\
\text { CS56 }\end{array}$ & Invitrogen & $\begin{array}{l}\text { mouse } \\
\text { monoclonal } \\
\text { IgM }\end{array}$ & MA183055 & $1: 200$ & Jeffrey et al. 2018 \\
\hline $\begin{array}{l}\text { anti- } \\
\text { GFAP }\end{array}$ & R\&D systems & $\begin{array}{l}\text { mouse } \\
\text { monoclonal } \\
\text { lgM }\end{array}$ & MAB2594 & $1: 100$ & $\begin{array}{l}\text { The specificity validated } \\
\text { using knockout } \\
\text { validation }\end{array}$ \\
\hline $\begin{array}{l}\text { anti- } \\
\text { MAP-2 }\end{array}$ & Invitrogen & $\begin{array}{l}\text { mouse } \\
\text { monoclonal } \\
\text { IgM }\end{array}$ & $13-1500$ & $1: 300$ & Sharma et al. 2017 \\
\hline $\begin{array}{l}\text { anti- } \\
\text { CS-A }\end{array}$ & Seikagaku & $\begin{array}{l}\text { mouse } \\
\text { monoclonal } \\
\text { IgM }\end{array}$ & LY111 & 1:1000 & Simona et al. 2017 \\
\hline $\begin{array}{l}\text { anti- } \\
\text { CS-C }\end{array}$ & Seikagaku & $\begin{array}{l}\text { mouse } \\
\text { monoclonal } \\
\text { lgM }\end{array}$ & MC21 & $1: 1000$ & Simona et al. 2018 \\
\hline $\begin{array}{l}\text { anti-5- } \\
\text { HT }\end{array}$ & ImmunoStar & $\begin{array}{l}\text { rabbit } \\
\text { polyclonal } \\
\text { lgM }\end{array}$ & 1394 & $1: 100$ & Jung-Yu et al. 2006 \\
\hline $\begin{array}{l}\text { anti-5- } \\
\mathrm{HT}_{2 \mathrm{c} / \mathrm{a}}\end{array}$ & Abcam & $\begin{array}{l}\text { rabbit } \\
\text { polyclonal } \\
\text { lgM }\end{array}$ & ab37293 & $1: 100$ & Philippa et al. 2018 \\
\hline $\begin{array}{l}\text { anti-5- } \\
\mathrm{HT}_{7}\end{array}$ & Abcam & $\begin{array}{l}\text { rabbit } \\
\text { polyclonal } \\
\text { IgM }\end{array}$ & ab61563 & $1: 200$ & \\
\hline $\begin{array}{l}\text { anti- } \\
\text { RPTPo }\end{array}$ & R\&D systems & $\begin{array}{l}\text { goat } \\
\text { polyclonal } \\
\text { lgM }\end{array}$ & AF3430 & $1: 100$ & Mattias et al. 2020 \\
\hline $\begin{array}{l}\text { anti- } \\
\text { LAR }\end{array}$ & Abcam & $\begin{array}{l}\text { goat } \\
\text { polyclonal } \\
\text { lgM }\end{array}$ & ab118456 & $1: 100$ & \\
\hline $\begin{array}{l}\text { anti- } \\
\text { C4ST- } \\
1\end{array}$ & Invitrogen & $\begin{array}{l}\text { rabbit } \\
\text { polyclonal } \\
\text { lgM }\end{array}$ & PA5-62697 & $1: 200$ & \\
\hline
\end{tabular}

\section{Figures}


A

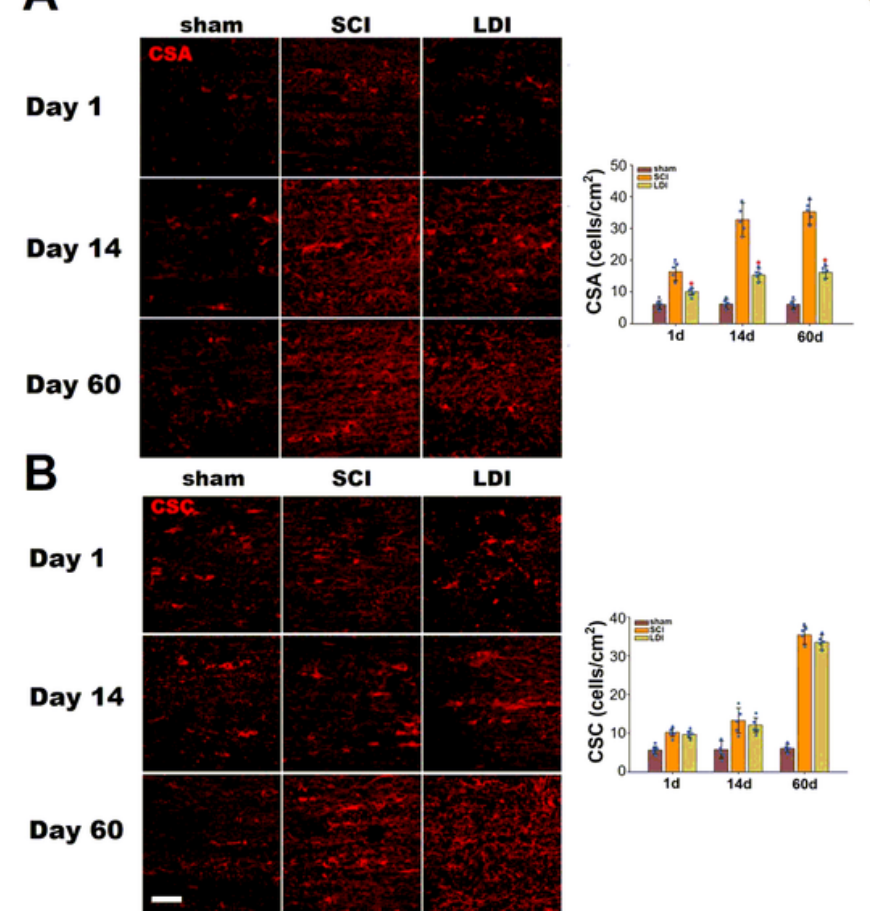

C

Day 14

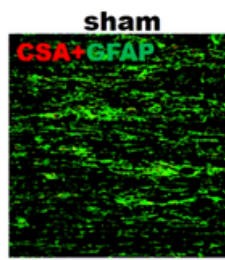

CSA+MAP-2
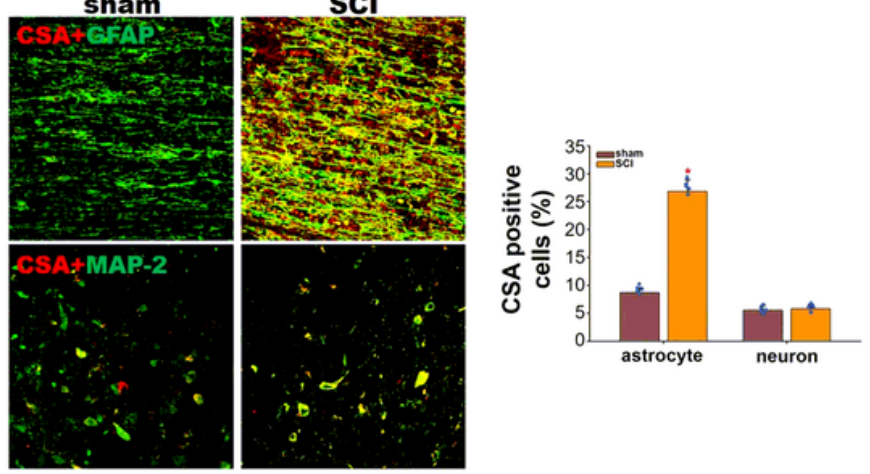

Day 60
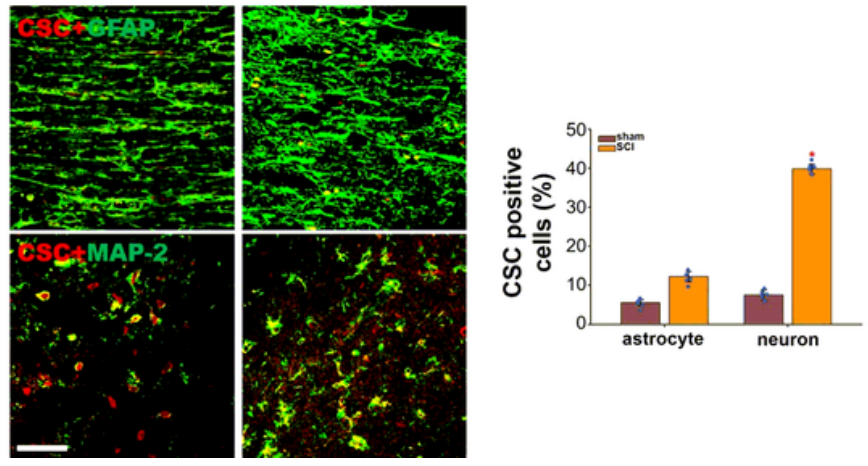

Figure 1

The temporal expression and cellular localization of CS-A and CS-C proximal to the lesion following SCI. (A) Immunofluorescent staining showing that CSA expression was induced after $\mathrm{SCl}(\mathrm{n}=5)$ and was strongly attenuated by LDI $(n=5)\left({ }^{*}<<0.05\right)$. (B) Although CS-C increased at 14 -days post-SCI $(n=5)$ and reached a peak at 60-days post-SCI, LDI treatment $(n=5)$ showed no inhibitory effect on CS-C expression. Scale bar $=50 \mu \mathrm{m}$. (C) At 14-days post-SCI $(n=5)$, colocalization of CS-A and GFAP was also apparent, but rare expression of CS-A was observed in MAP-2 positive neurons/axons. At 60-days post-SCI(n=5), CS-C was upregulated in both neuron/axons and astrocytes proximal to the lesion $\left({ }^{*} P<0.05\right)$. Scale bar $=50$ $\mu \mathrm{m}$. 


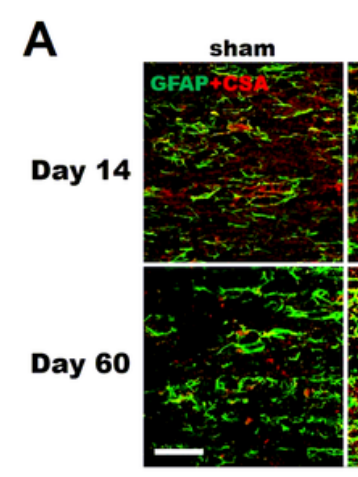

B

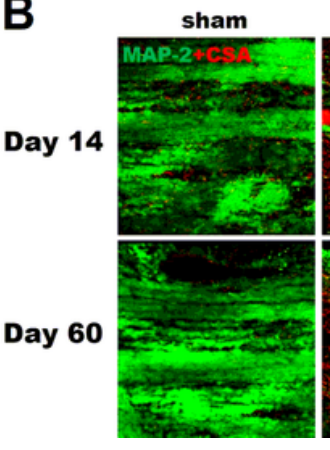

scI

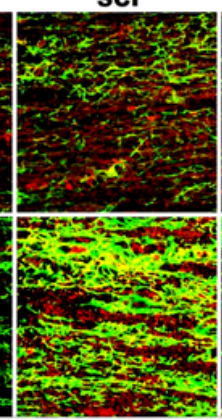

SCI

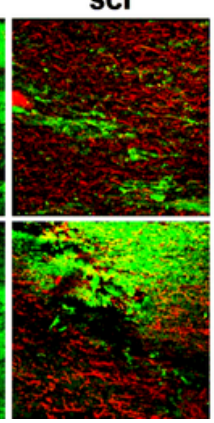

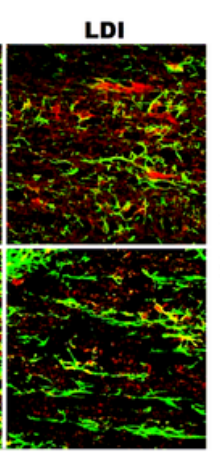

LDI

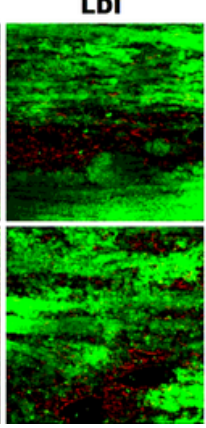

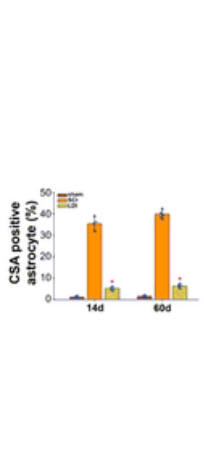

D

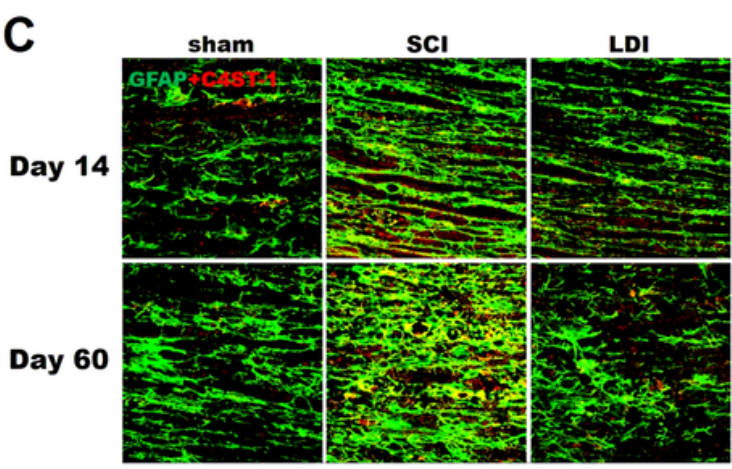

D

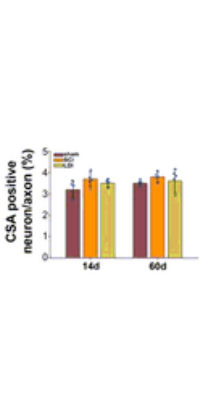

\section{Figure 2}

LDI decreases astrocyte-associated CS-A expression after SCI. (A) Representative GFAP (green)/CSA (red) double-staining images. Immunofluorescent staining showing that GFAP and CSA expression were induced after $\mathrm{SCI}(\mathrm{n}=5)$ and were strongly attenuated by $\operatorname{LDI}(n=5)\left({ }^{*} \mathrm{P}<0.05\right)$. Scale bar $=50 \mu \mathrm{m}$. (B) Representative MAP-2 (green)/CSA (red) double-staining images. Immunofluorescent staining showing that $\mathrm{LDI}(\mathrm{n}=5)$ had no effect on neuron-associated CS-A expression ( $\left.{ }^{*}<0.05\right)$. Scale bar $=50 \mu \mathrm{m}$. (C) Representative GFAP (green)/C4ST-1 (red) double-staining images. Immunofluorescent staining showing that LDI treatment $(n=5)$ significantly inhibited C4ST-1 expression in astrocytes ( $\left.{ }^{*} P<0.05\right)$. Scale bar $=50$ $\mu \mathrm{m}$. (D) Immunoblotting results of C4ST-1 in sham-operated, SCl, and LDI groups at 14 - and 60 -days post$\mathrm{SCl}\left({ }^{\star} \mathrm{P}<0.05\right)$. 


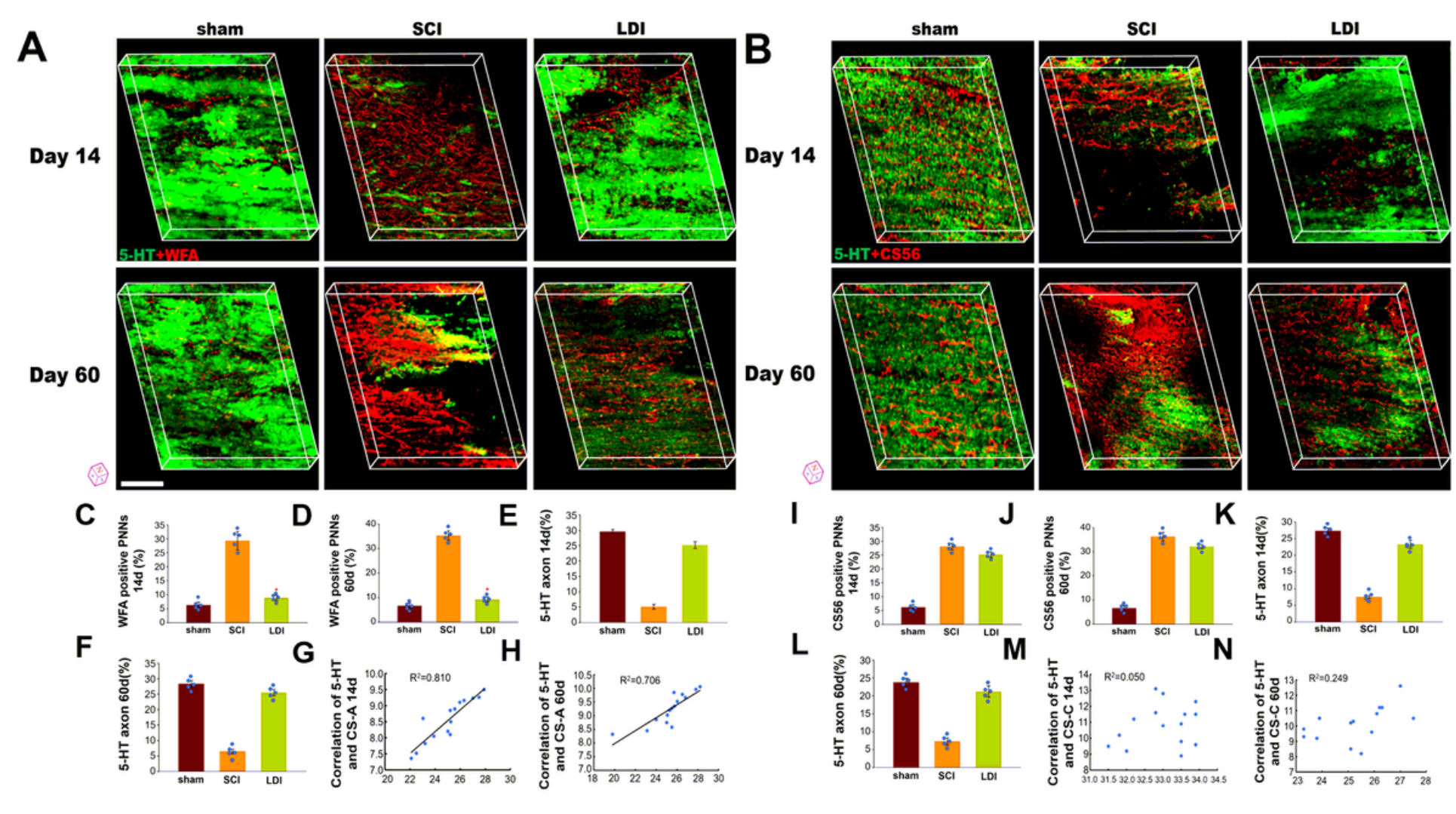

Figure 3

LDI promotes 5-HT axons expression accompanied with decrease of CS-A-enriched PNNs. In the SCI group $(n=5), 5-H T$ axons were repelled in a comparable manner to CS-A-enriched PNNs (A) and CS-Cenriched PNNs (B) proximal to the lesion. $\mathrm{LDI}(\mathrm{n}=5)$ significantly reversed CS-A-enriched PNN accumulation and and promoted 5-HT-positive axonal regeneration ( $\left.{ }^{*} \mathrm{P}<0.05\right)$, but no inhibitory effect on CS-C-enriched PNN accumulation. Scale bar $=50 \mu \mathrm{m}$. (C-F) The percentage of WFA positive PNNs and 5$\mathrm{HT}$ axon at 14-days and 60 days post-SCI $(n=5) .(\mathrm{G}, \mathrm{H})$ There was a significant correlation between a reduction of CS-A-enriched PNNs and an increase of 5-HT axonal immunoreactivity. (I-L) The percentage of CS56 positive PNNs and 5-HT axon at 14-days $(n=5)$ and 60days $(n=5)$ post-SCl. $(M, N)$ There was no significant correlation between a reduction of CS-C-enriched PNNs and an increase of 5-HT axonal immunoreactivity. 

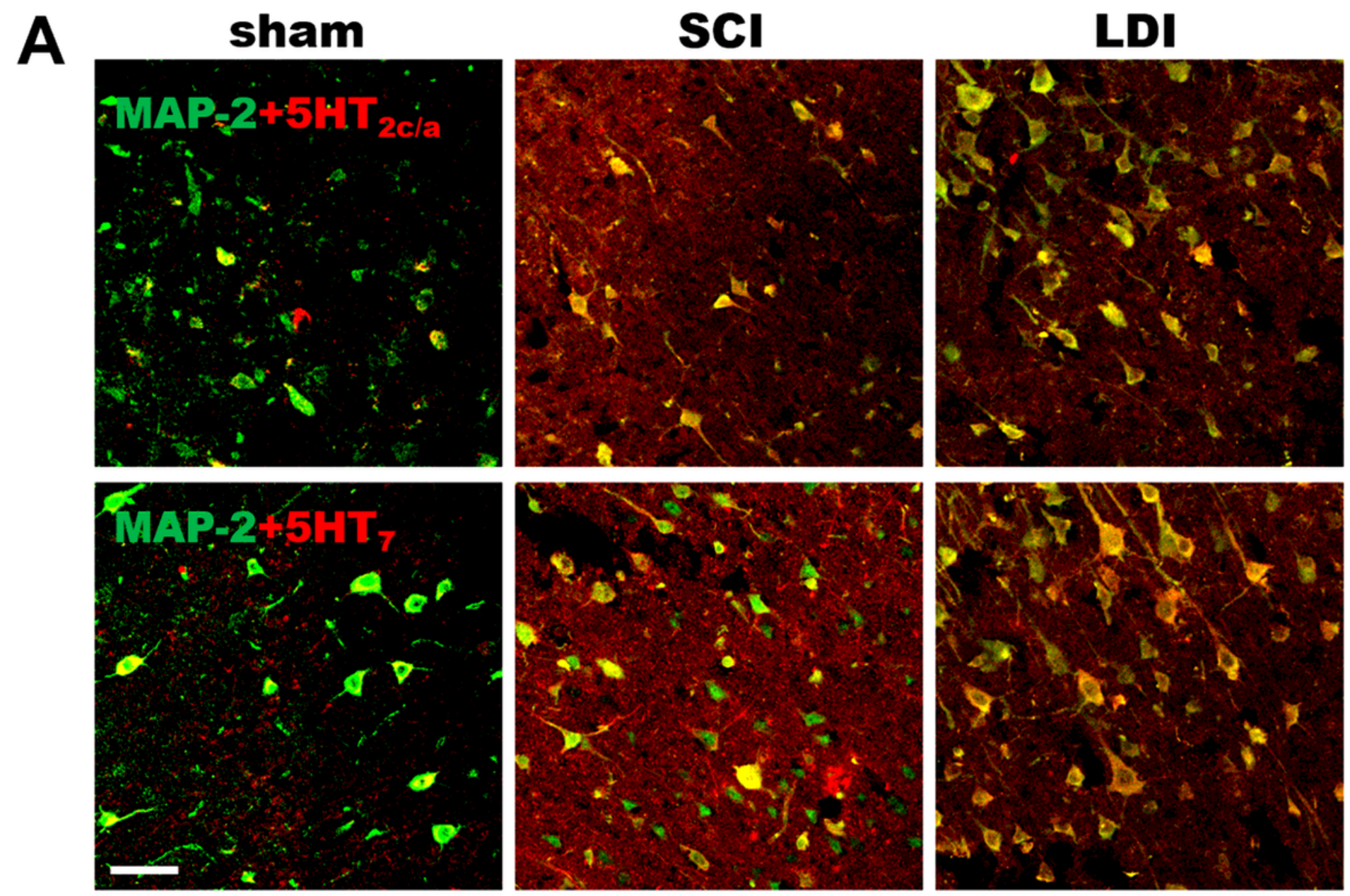

B
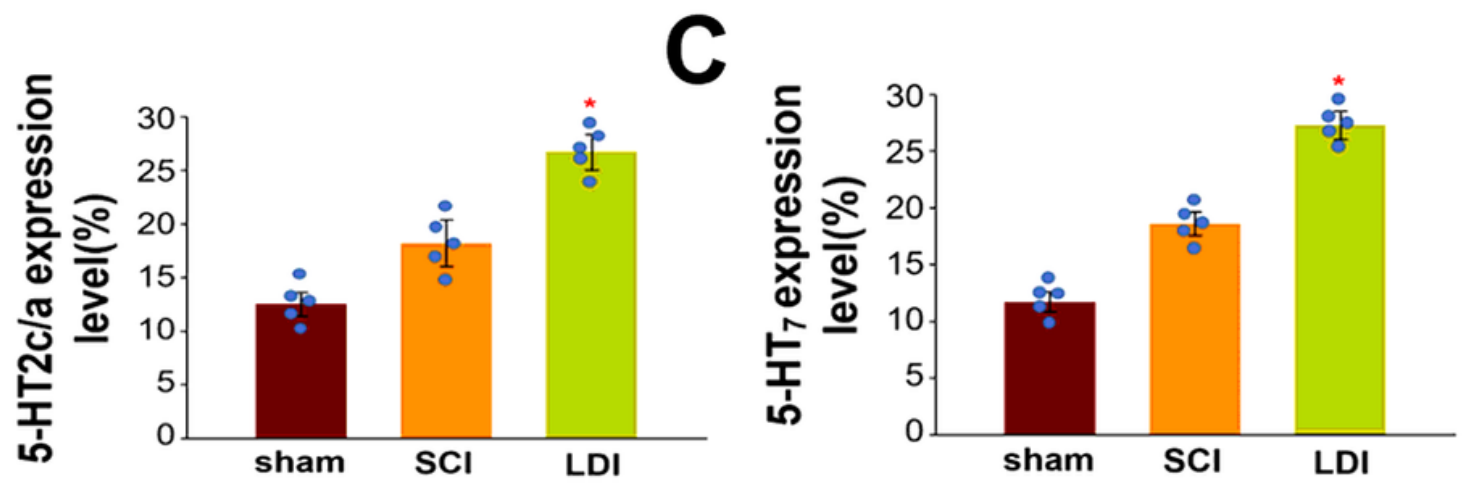

Figure 4

LDI increases 5-HT receptor expression after SCl. (A) Representative MAP-2 (green)/5-HT2c/a (red, A) and 5-HT7 (red, B) double-staining images. Immunofluorescent staining showed that $\mathrm{LDI}(\mathrm{n}=5)$ increased $5-\mathrm{HT}$ receptor expression in neurons. Scale bar $=50 \mu \mathrm{m}$. (B) The 5-HT2c/a expression levels in shamoperated( $(n=5), S C I(n=5)$ and LDI $(n=5)$ groups $\left({ }^{\star} P<0.05\right)$. (C) The 5-HT7 expression levels in shamoperated $(n=5), S C I(n=5)$ and $\operatorname{LI}(n=5)$ group $\left({ }^{*}<<0.05\right)$. 
A

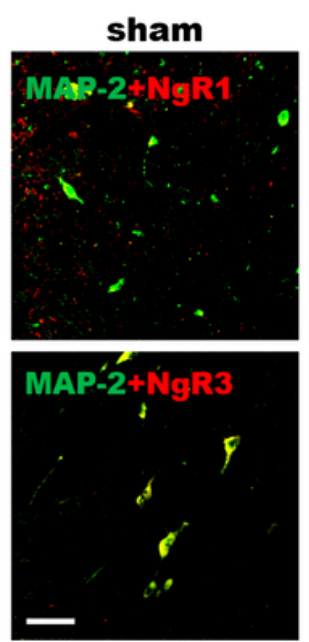

C

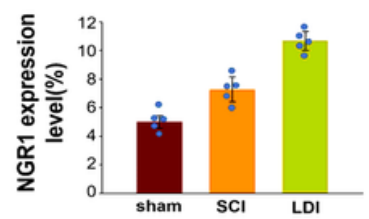

SCI
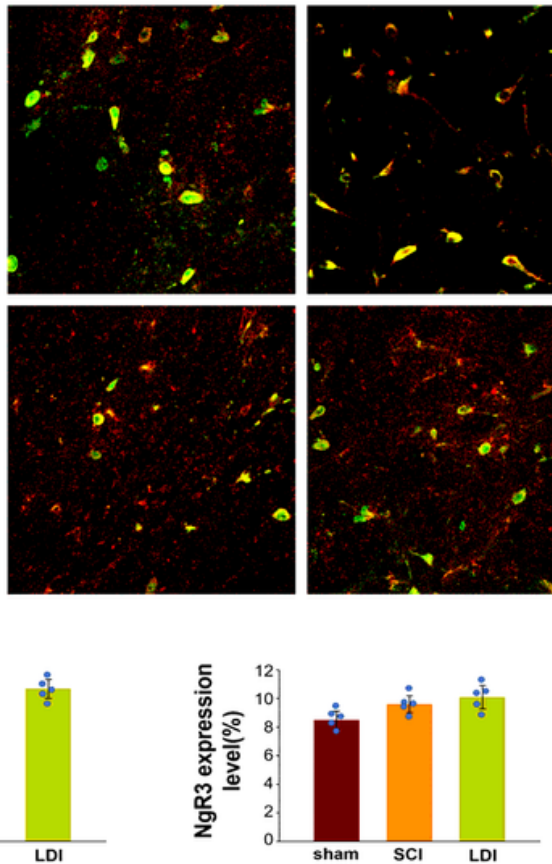

B
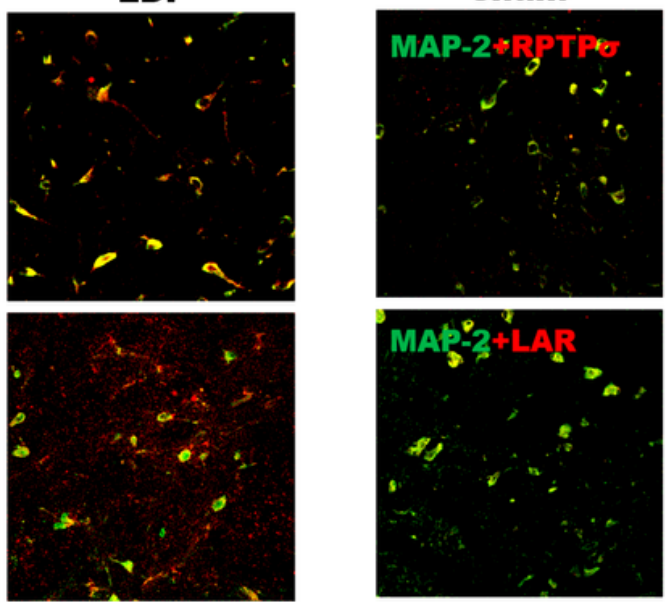

D

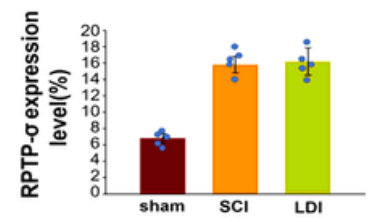

SCI
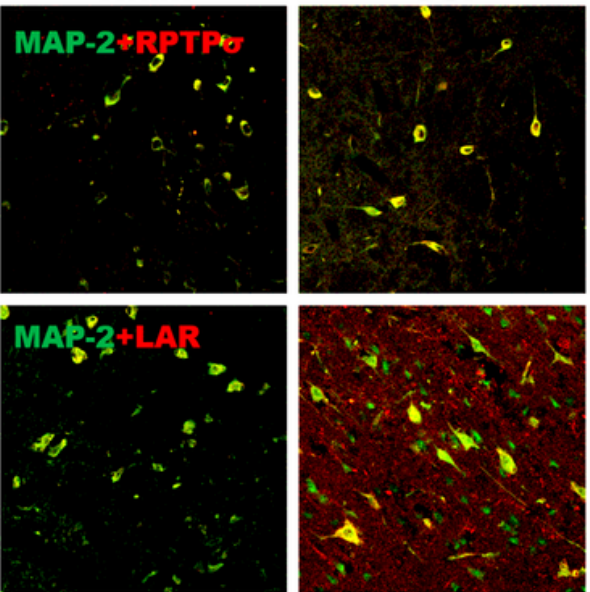
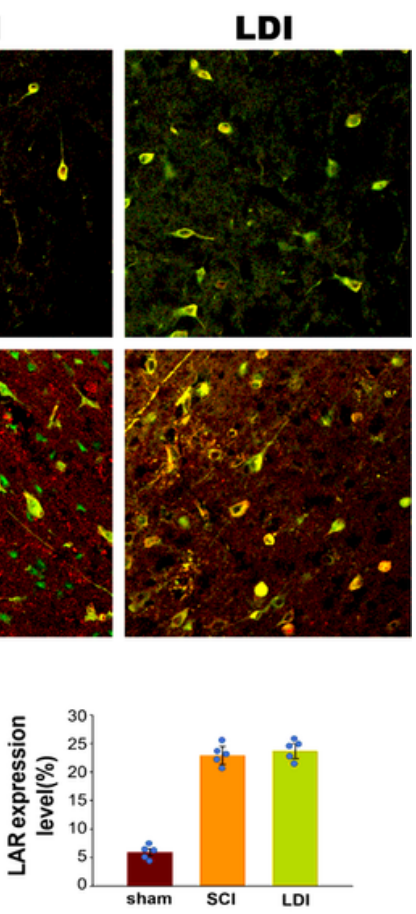

Figure 5

LDI has no effect on NgR, RPTPo or LAR receptors after SCI. (A, C) Representative MAP-2 (green)/NgR (red) double-staining images. There was no significant difference in the expression of NgR1 or NgR3 between the $\mathrm{SCl}$ group $(n=5)$ and $\mathrm{LDI}(\mathrm{n}=5)$ group. Scale bar $=50 \mu \mathrm{m} .(\mathrm{B}, \mathrm{D})$ Representative MAP-2 (green)/RPTP $\sigma$ and LAR receptor (red) double-staining images. There was no significant difference in the expression of RPTP $\sigma$ or LAR between the $S C I$ group $(n=5)$ and LDI group $(n=5)$. Scale bar $=50 \mu \mathrm{m}$. 


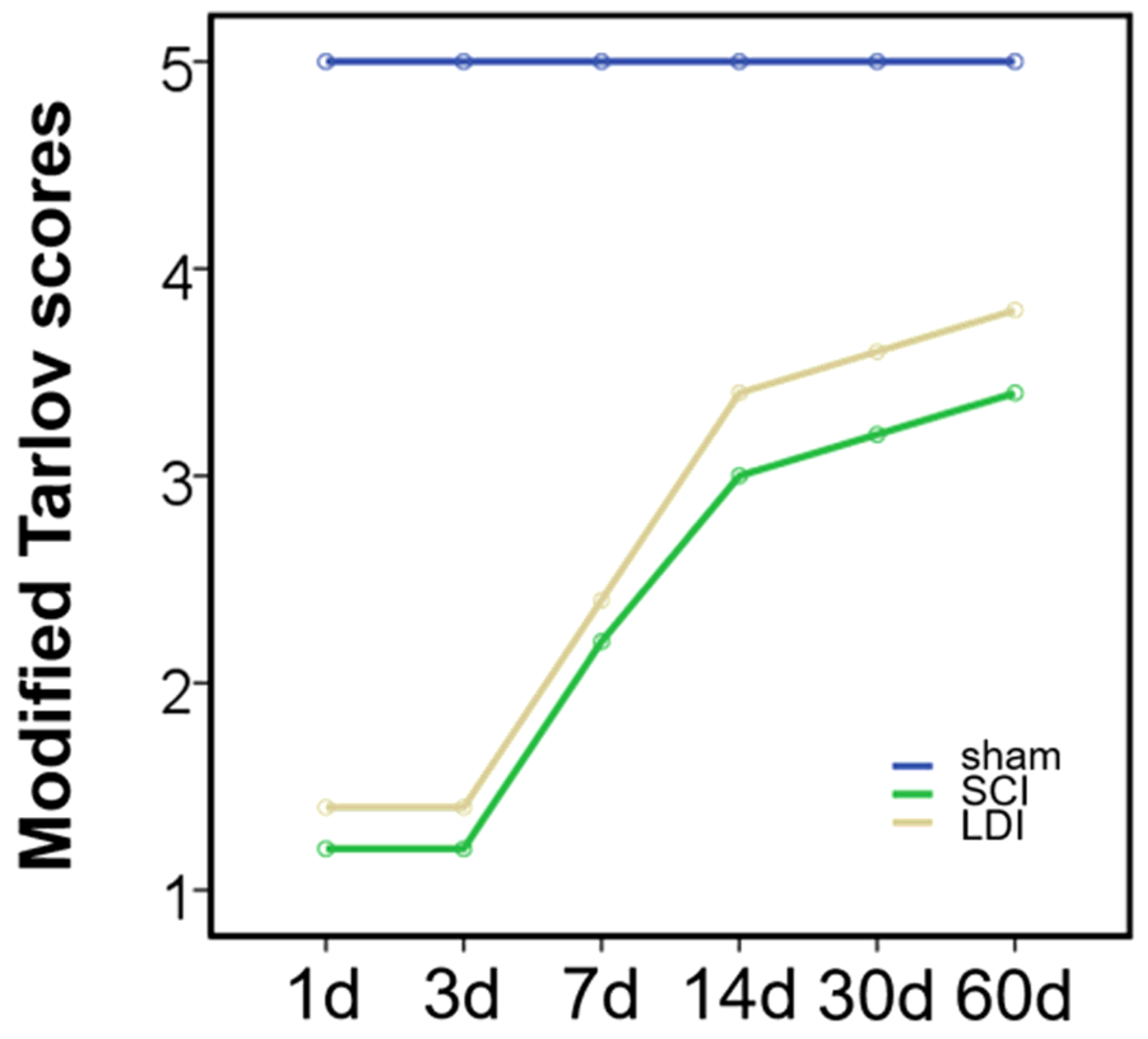

Figure 6

LDI promotes motor-function recovery after SCl. Enhanced motor recovery occurred in the LDI-treated animals compared with the SCl-treated animals. The modified-Tarlov scores of sham-operated $(n=5)$, $\mathrm{SCl}(n=5)$, and LDI $(n=5)$ groups at 1-, 3-, 7-, 14-, 30- and 60-days post-SCl are shown $\left({ }^{\star} P<0.05\right)$.

\section{Supplementary Files}

This is a list of supplementary files associated with this preprint. Click to download.

- S1.normalityandvariancehomogeneity.docx 
- S2.Fullwesternblotbandsfilm.pptx 